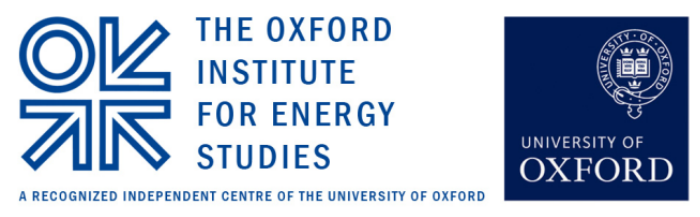

\title{
The Oxford Approach
}

Operationalizing the UNFCCC Principle of 'Respective Capabilities'

Benito Müller and Lavan Mahadeva

EV 58

February 2013 
The contents of this paper are the authors' sole responsibility. They do not necessarily represent the views of the Oxford Institute for Energy Studies or any of its members.

Copyright (C) 2013

\section{Oxford Institute for Energy Studies}

(Registered Charity, No. 286084)

This publication may be reproduced in part for educational or non-profit purposes without special permission from the copyright holder, provided acknowledgment of the source is made. No use of this publication may be made for resale or for any other commercial purpose whatsoever without prior permission in writing from the Oxford Institute for Energy Studies.

ISBN

$978-1-907555-68-8$

\section{Authors}

Dr Benito Müller is Director, Energy and Climate Change, at the OIES, and Managing Director of Oxford Climate Policy. A list of his publications can be found at www.OxfordClimatePolicy.org.

Email: benito.muller@oxfordenergy.org.

Dr Lavan Mahadeva is Senior Research Fellow, at the OIES.

Email: lavan.mahadeva@ oxfordenergy.org.

\section{Acknowledgments}

We would like to thank, without implication, Christopher Allsopp, Tom Athanasiou, Sivan Karta and the participants of the 2012 ecbi Oxford Seminar for their valuable comments.

The data accompanying this paper are available at www.oxfordenergy.org/publications/oxford-capability-data-2009/ 


\section{Table of Contents}

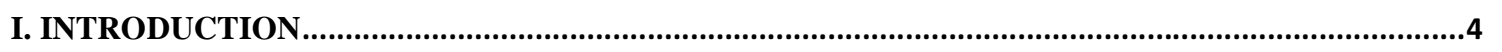

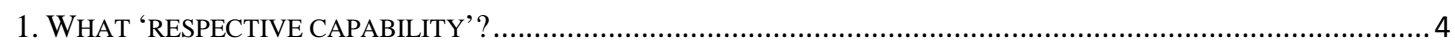

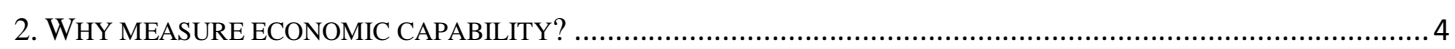

II. THE OXFORD CAPABILITY MEASURE AND INDEX ............................................................6

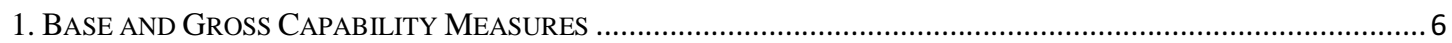

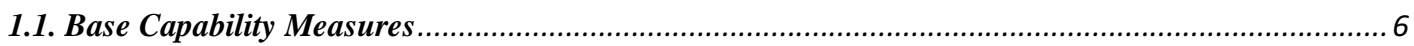

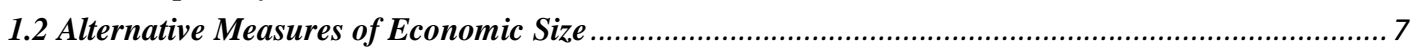

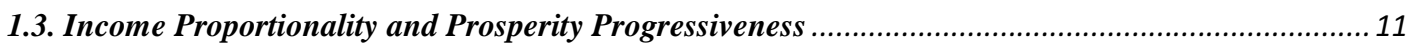

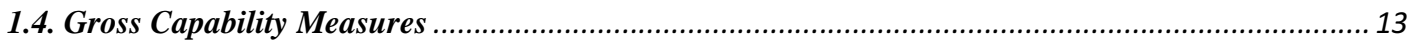

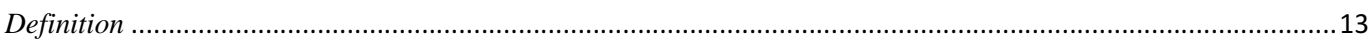

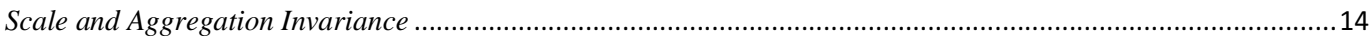

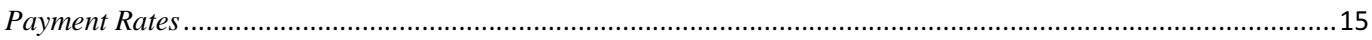

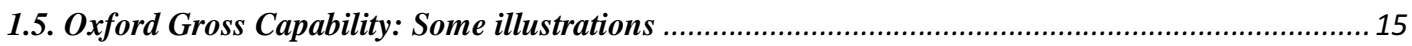

2. NET CAPABILITIES: POVERTY ALLOWANCES AND POVERTY AdJUSTED CAPABILITY ………………........... 18

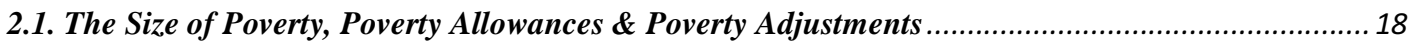

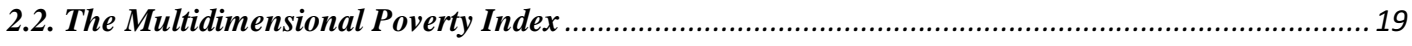

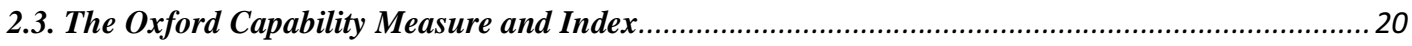

III. THE GREENHOUSE DEVELOPMENT RIGHTS (GDR) APPROACHES .....................................23

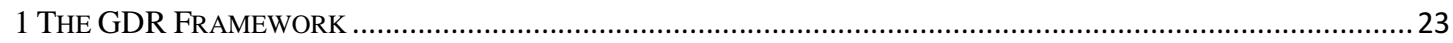

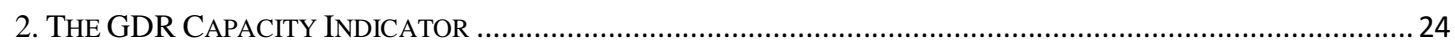

3. From NATIONAL DEVELOPMENT Claim RighTS To GLOBAL Rich OBLIGATIONS...........................................2

IV. THE OXFORD MEASURE: DISCUSSION AND ILLUSTRATIVE EXAMPLES ..............................32

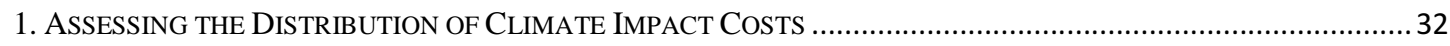

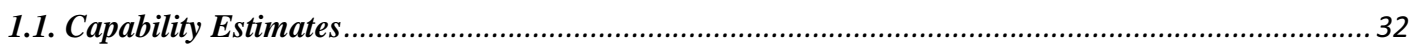

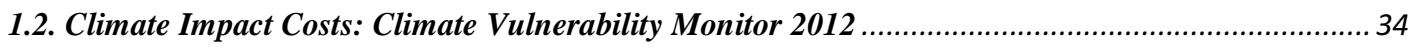

1.3. Cost Distribution, Capability Distributions, Excess Costs, and Degrees of Inequity......................... 36

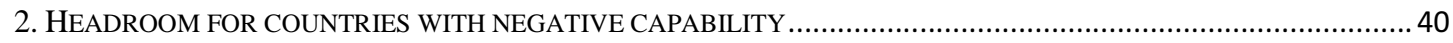

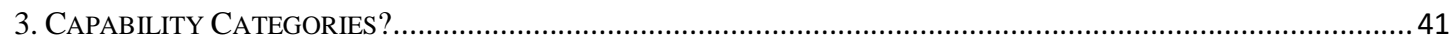

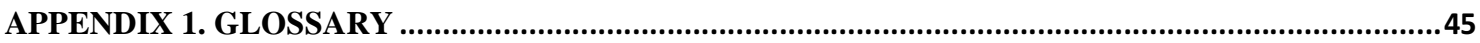

APPENDIX 2. ESTIMATING THE POWER OF PROSPERITY PROGRESSIVITY ( $(\Delta)$........................47

APPENDIX 3. THE POVERTY CAPABILITY ALLOWANCE (I) .....................................................50

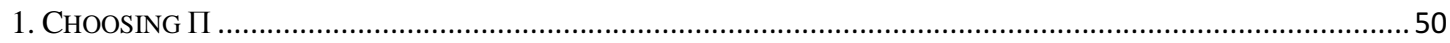

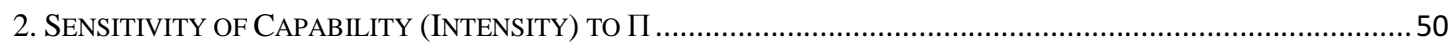




\section{Introduction}

\section{WHAT 'RESPECTIVE CAPABILITY’?}

Article 3.1 of the UN Framework Convention on Climate Change (UNFCCC) stipulates that Parties 'should protect the climate system ... in accordance with their common but differentiated responsibilities and respective capabilities' (usually referred to as 'CBDR' and ' $\mathrm{RC}$ ', respectively). There are strong (albeit not uncontested ${ }^{1}$ ) reasons to believe that this stipulation will be central in the deliberations of the UNFCCC ad hoc Working Group on the Durban Platform for Enhanced Action (ADP).

Regrettably, there is no consensus as to the meaning of this proviso. In particular, its references to 'responsibilities' and 'capabilities' are notoriously ill-specified: 'Capability' - the theme of this paper - can refer to many different things. There is 'institutional capability', 'technological capability', or 'economic capability', to name just a few. These capabilities will generally be interrelated, and it stands to reason that they (and others) will have to be taken into account jointly in applying the Art. 3.1 RC-principle. However, the focus of this paper is deliberately only on 'economic capability' in the sense of a country's 'ability to pay' (for the protection of the climate system) - based on its income, modified by other economic factors - which we take to be the most important of the capabilities relevant to interpreting Article 3.1.

\section{WHY MEASURE ECONOMIC CAPABILITY?}

Why would one wish to measure (respective) abilities to pay for the protection of the climate system? According to (one reading of) the proviso in Art. $3.1 \mathrm{RC}$, the issue at stake is a just international distribution of the cost/burden of protecting the climate system. ${ }^{2}$ Under an Aristotelian interpretation of distributive justice, ${ }^{3}$ this means that burdens should be proportional to (a combination of) countries' differentiated responsibilities (for the climate change problem) and their respective capabilities (to deal with the problem). ${ }^{4}$ To become operational, this reading requires numerical representations ('measures') for the relevant country capabilities (and responsibilities). ${ }^{5}$ Accordingly, the rationale for introducing a numerical measure of countries' ability to pay, in this study, has been the need to be able to judge whether proposed climate change cost/burden distributions are fair or just (in the mentioned Aristotelian sense). ${ }^{6}$

\footnotetext{
${ }^{1}$ The lack of an explicit reference to these principles in the Durban Platform decision was seen by some as an indication that they are not relevant to the ADP negotiations. However, the discussions so far indicate otherwise.

2 'Principles of distributive justice are normative principles designed to guide the allocation of the benefits and burdens of economic activity.'[Stanford Encyclopaedia of Philosophy, http://plato.stanford.edu/entries/justicedistributive]

3 'This, then, is what the just is - the proportional; the unjust is what violates the proportion.' [Nicomachean Ethics, Book V]

${ }^{4}$ This interpretation is based on the 'polluter pays' idea with respect to the use of differentiated responsibilities (in the sense of liabilities), and '(mandated) solidarity' with reference to respective capabilities.

${ }^{5}$ The measurement of differentiated responsibilities turns out to be considerably simpler than that of respective capabilities (see, for example, Benito Müller, Niklas Höhne, and Christian Ellermann, Differentiating (Historic) Responsibilities for Climate Change, October 2007, www.oxfordclimatepolicy.org/publications/documents/ DifferentiatingResponsibility.pdf).

${ }^{6}$ Countries that do not have the institutional capacity to deal with the problem should (be supported to) build that capacity, and possibly be given a temporary waiver to being obliged to carry their otherwise fair share of the burden/effort, but the degree of institutional capacity should not itself be reflected in calculating how much of the burden countries should be expected to shoulder. Factoring performance measures - such as those captured in the IDA Country Performance Ratings (CPR) - into allocative formulae can lead to fatal flaws. For
} 
To be quite clear, such proposals will, and most likely should, not only involve other (Aristotelian) proportionality factors - such as differentiated responsibilities - but also (more qualitative) considerations leading, for example, to ex ante exemptions from sharing the relevant costs/burdens. This means, in particular, that the capability measures introduced in this paper are not meant to introduce country categories, apart possibly from the trivial distinction between countries with some (positive) capability, and those with none. They are intended to contribute to methodologies aimed at ascertaining whether distributions of costs/burdens associated with the global climate change effort are just/fair or not. ${ }^{7}$

Finally, it must be emphasized that having established what would be fair cost shares does not mean there is a moral entitlement to reject climate change actions just because they would incur costs over and above this share. All that one is entitled to reject is being obliged to shoulder the cost of these additional actions. For example, having zero capability does not entitle a country to behave as if climate change does not exist. Countries should be open to engage in the global effort, but they have the right to expect that the (additional) costs for these activities are shouldered by those with economic capability.

more on this, see B. Müller, Performance Based Resource Allocation: Lessons from multilateral funds, Oxford Energy and Environment Brief, forthcoming.

${ }^{7}$ This means, in particular, that equal/different capability is generally, on its own, insufficient to use when drawing conclusions about equal or different treatment. Such conclusions can only be drawn under certain ceteris paribus framing conditions. 


\section{The Oxford Capability Measure and Index}

In this part we introduce a quantitative measure of a country's economic capability to pay. The definition of this measure is modelled on the well-known methodologies used to assess a people's taxable income (income tax liability) - their 'income tax capability', as it were. Starting with the most familiar measure of economic size (GDP), the measure is first progressively adjusted to reflect differences in average income levels (GDP per capita), leading to the measure of a country's 'gross capability' (akin to individuals' gross taxable income).

A further adjustment is then introduced to reflect the domestic obligation generally acknowledged to take precedence over international obligations regarding sharing the cost of climate change: the obligation to address/eradicate domestic poverty. Following the income tax paradigm, this is done by allocating 'poverty capability allowances' (in proportion to the number of poor people and the poverty intensity) to be deducted from the figure for gross capability. The resulting (net) amount is the Oxford Capability Measure (OCM). The percentage shares - referred to as the Oxford Capability Index (OCI) - of the sum of positive OCM amounts are used to determine the fair/just cost shares of countries, as mentioned in the preceding section (countries with negative OCM values are assigned a zero per cent share).

\section{BASE AND GROSS CAPABILITY MEASURES}

\subsection{Base Capability Measures}

It stands to reason that, in a completely homogeneous world - a world where every individual is equally well/badly off, and all (per capita) socio-economic country indicators are the same - a country's capability to pay should be proportional to its overall (economic) size, ${ }^{8}$ thus implying (in the context of the above-mentioned Aristotelian approach) that it would be fair/just to expect countries to pay the same if, and only if, they are the same size. ${ }^{9}$ To put it differently, if the world were completely homogeneous, then a country's overall size would be a fair measure of its capability to pay. This means that if - as we propose ${ }^{10}$ - economic size is measured by a country's Gross Domestic Product (GDP) (at current purchasing power parity dollars), then the (hypothetical) homogeneous Base Capability Measure (BCM) of a country $k$ is formally given as: ${ }^{11}$

$$
B C M_{k}={ }_{\text {def }} G D P_{k}^{12}
$$

The problem is: the world is not homogeneous - far from it. This is why, for it to be adequate in a heterogeneous context, this base measure needs to be adjusted. Our main task in developing an adequate measure for 'country capability to pay' is accordingly the identification of salient country differences and the consequent adaptation of the hypothetical homogeneous measure. We will continue this in Section II.1.3, but before we can do so, we need to look a little more closely at the question of what measure should be used to capture 'overall economic size' in this context.

\footnotetext{
${ }^{8}$ Given that the homogeneity is meant to be reflected in equal per capita GDP for all countries, the economic size is of course proportional to the population size.

${ }^{9}$ Note that in such a homogeneous world, countries with the same GDP will also have the same population size, and vice versa.

${ }^{10}$ Alternative measures of economic size will be discussed in Section II.1.2

${ }^{11}$ It is easy to see that, as such, this measure is trivially income proportional: $B C M_{k}: B C M_{m}=G D P_{k}: G D P_{m}$.

${ }^{12}$ Note that, strictly speaking, the formalization ought to have a temporal parameter, i.e. capability or GDP of $k$ at time $t\left(B C M_{k, t}\right.$ and $\left.G D P_{k, t}\right)$, but for the present purposes we can assume the time parameter is given implicitly.
} 


\subsection{Alternative Measures of Economic Size}

At the heart of any scheme to determine the just international distribution of the costs of protecting the climate system must be some base measure of national economic size. In our operationalization, GDP acts as our base measure and performs a role analogous to that of a tax base in a tax system: the ratio of two countries' GDPs determines the ratio of their base capabilities (to pay). ${ }^{13}$

In this section, we explore other measures of this national 'tax base'. Essentially there are two criteria that should determine what a good measure for this purpose should be: first, it should give an appropriate indication of the resources available to each country; second, it should be feasible to construct a data set using a minimum number of non-contentious and uncertain parameters. As we shall see, some alternative measures could imply a different distribution of base capabilities to that given by GDP. Nevertheless, it is reassuring that our approach can be applied across the range of these measures. Thus, as important as this decision could be, we should be clear that it is not critical to the merits of our approach.

\section{Annuity wealth measure}

Our scheme works as a pay-as-you go tax system: capability varies with economic size, just as an individual's income tax base is expected to alter with their income. This can be contrasted with an annuity payment based on a one-off assessment of a nation's wealth, which is then only revised as new information comes to light. ${ }^{14}$ If we simplify the productive factors at a nation's command into labour and capital, a nation's wealth is equal to the sum of the real values of capital and the discounted sum of current and future labour income. As all revenue is ultimately for consumption, economic wealth is also equal to the discounted sum of current and future consumption. These linked equivalences provide the justification for using an annuity measure of national wealth as a measure of economic size. ${ }^{15}$

Notwithstanding any intellectual appeal that one might draw from the theoretical definition of economic wealth, deriving a comparative national database of the concept would be a very formidable exercise. There are two directions from which the calculation can be approached. One tactic would be to estimate each country's labour revenue stream and capital stock. The other would be to forecast a path for each country's consumption. In either case, a very long-horizon forecast of the future economic prospects of each nation must be carried out. Judging from past history, the extent of uncertainty in this type of exercise is likely to be large. Moreover, the sustainability of the mean path should be a part of the assessment of wealth-based economic capability: substantially complicating the calculations. In addition, as these streams need to be converted to present values, there will be disputes about the values of discount rates, across countries and over time.

Temporary fluctuations in income should, intrinsically, be smoothed in a present value wealth measure, and this relative constancy might be perceived as an advantage of such a measure. However, given the huge subjectivity in such calculations, estimates of wealth should still be expected to shift periodically as they are revised to reflect new evaluations. To take an example, we can consider

\footnotetext{
${ }^{13}$ The analysis of the choice of base measure contained in this section distances itself from considerations of vertical equity or poverty. We show briefly below how an appropriate base measure can allow for vertical equity considerations to reach a figure for gross capability. Later on, we explain the next step - incorporating poverty as a salient feature regarding a country's capability to pay - to arrive at our final Oxford measure.

${ }_{15}^{14} \mathrm{An}$ annuity is a stream of fixed payments that terminates at some specified date.

${ }^{15}$ In general, however, the ratio of the economic wealth of two countries is not equal to the ratio of their intertemporal social welfares and thus there is no obvious utilitarian welfare justification for basing capability on wealth.
} 
revisions in the World Bank's Wealth of Nations project. The data set contains estimates of total wealth for 152 countries at the three points in time: 1995, 2000, and $2005 .{ }^{16}$ We can see that the USA-China wealth ratio has fallen over successive measurements (1995 to 2000 to 2005) from 13 to 10 to 9 and will no doubt fall further once data from the financial crisis is incorporated in subsequent releases.

On these grounds, we have concluded that a pay-as-you-go income scheme is to be preferred to an annuity wealth measure at least on practical grounds. This leads us to restrict our attention to alternative measures of national income. ${ }^{17}$

\section{Use of PPP or Market Exchange Rates}

As our measure of economic size is used for international comparison, there is also an important decision concerning whether to convert each country's local currency measure of size using purchasing power parity (PPP) rates or to use market exchange rates. The PPP rate measures the number of units of a country's currency that are required to purchase the same quantity of goods and services (included in GDP) as one US dollar will purchase in the USA. Because the cost of purchase of domestic services is typically cheaper in poorer countries, this is then crucial for a relative measure economic size. For example, the USA-China GDP ratio on a current PPP basis in 2009 is 1.6, whereas using market exchange rates, it is 2.8 .

Given the scale of these differences, it is important to find some basis on which to choose between a PPP measure and a current dollar measure. A natural approach would be to ask what the climate fund contribution would instead have been spent on. The most straightforward answer is that this would be domestic expenditure and thus the value of the ability to pay should be in terms of the domestic expenditure basket. ${ }^{18}$ Hence, a purchasing power parity conversion should be more appropriate than nominal exchange rates.

\section{Gross National Income or Gross Domestic Product}

Another decision has to be made as to whether to base capability on Gross National Income (GNI) or Gross Domestic Product (GDP). Formally the two are related according to:

$$
\mathrm{GNI}=\mathrm{GDP}+\text { net income receipts from abroad }
$$

\footnotetext{
${ }^{16}$ The World Bank calculates total national wealth by accumulating estimates of consumption using a discount rate fixed in time and common to all countries. The total figure is broken down into the contributions of financial assets, physical capital, natural assets, and intangible capital using information on some components. Value changes are separated out from active savings. See The Changing Wealth of Nations, World Bank, Washington D.C., 2011.

${ }^{17}$ One could instead argue that consumption rather than income should measure economic size for capability; i.e., some if not all forms of savings from income should be exempt. Famously, Hobbes argued, 'For what reason is there that he which laboureth much and, sparing the fruits of his labour, consumeth little should be more charged than he that, living idly, getteth little and spendeth all he gets; seeing the one hath no more protection from the Commonwealth than the other?' [Leviathan, Hobbes, T. 1651]. There may also be difficulties in distinguishing between investment and consumption: for example with durables, health, and education. We bypass this debate here and note only that our scheme could equally well apply to a consumption measure of economic size.

${ }^{18}$ Most PPP calculations are in terms of consumption goods. We leave aside the issue as to the effect of absent Producer PPP data.
} 
Thus GNI adjusts the income earned in the national territory for factor payments earned by nonresident citizens. ${ }^{19}$ This means that while for many countries the two are likely to be close ${ }^{20}$ for countries with large net foreign asset positions (such as small islands), we should expect divergence. Also countries that make large interest payments on net liabilities (foreign debt, foreign bank loans, or foreign direct investment) will have less capability if economic size were based on GNI rather than GDP, all other things being equal. For example, in 2009, the ratio of US GNI to Ireland's GNI was 93 while the ratio of their GDPs was 77 (in the same PPP dollar terms). If we think the scheme should be indifferent as to the source of citizens' incomes wherever they are resident, there is a valid case to be made for the use of GNI instead of GDP.

\section{Net as opposed to Gross Product/Income}

Another dimension of choice could be a net, as opposed to a gross, income measure of economic size. This can be applied to either GDP or GNI, with the respective net measures being Net National Product or Net National Income. The difference between gross income and net income is capital consumption, together with other net additions to income-earning assets that can provide for future consumption. By virtue of making an adjustment for all forms of net savings, a net income measure is the actual increment to a nation's net resources which can be either consumed now or saved in a form which can provide for future consumption. ${ }^{21}$

Formally, Net National Income (NNI) is related to GNI according to the following:

Net National Income $=($ Gross National Income -

consumption of fixed capital) - other unrecorded net decreases in wealth. ${ }^{22}$

The consumption of fixed capital is familiar in other contexts as depreciation of physical capital. But the depletion of natural assets, price changes in unexploited subsoil assets, the depreciation of human capital due to ageing and health, and environmental degradation are also important ways in which the capacity of a country to provide future consumption changes, without being included in gross income at that moment in time.

Consider the trajectories of net and gross income as a natural resource is discovered and exploited. The discovery of a natural resource could imply a large rise in accounting net income at the time of discovery (equal to the present value of net revenue streams) or at the times when exploration investment was made. Alternatively, one could take the view that the wealth was always there and need not be accounted for, which would dramatically lower the capability of resource producers on a net compared to a gross basis. Certainly gross income will not necessarily rise at the time of discovery, but rather only at the points in time when the natural resource is extracted and sold internationally and then by the accrued revenues. Net income should, on the other hand, be relatively unchanged at those times of sale, recognizing that one type of asset (the resource) is only being

${ }^{19}$ Yet another measure, Gross Disposable National Income, adjusts GNI for net remittances, contributions to international funds, and aid payments (unrequited current transfers).

${ }^{20}$ In our data, the relative GDP per capita of 88 per cent of countries was within 10 per cent of their GNI per capita in 2009.

${ }^{21}$ The inadequacy of gross income measures for some purposes was recognized early on in the economic literature and is a recurrent theme in macroeconomics. See for example 'New Directions in National Economic Accounting, William D. Nordhaus, American Economic Review, Vol. 90, No. 2, Papers and Proceedings of the One Hundred Twelfth Annual Meeting of the American Economic Association, May, 2000, 259-63.

${ }^{22}$ Net National Income typically refers to Gross National Income minus consumption of fixed capital while here we have broadened it to adjust for other unrecorded changes in wealth. We have ignored the role of taxes on imports and exports. 
transformed to another (say, bank deposits). Another divergence could occur if, say, the price of that resource unexpectedly doubles (after discovery but without any being sold) and is expected to remain at this level thereafter. Then the country will experience a further increase (or rather revision) in wealth at that time, while gross income will only be affected when the resource is sold at the higher price. Thus the difference between the two is partly down to when and if net income records resource revenue.

Another scenario where net income is mentioned is where the capital consumption is not of a marketable asset, ${ }^{23}$ such as when strong economic activity (implying a strong gross output) damages the ecosystem. Net income would be lower because of the damage to the non-renewable environmental endowment. Indeed, there are many measures of net national income depending on how broad is the scope of the (typically negative) net savings that we wish to incorporate. Hence it is difficult to make general statements about ratios of net economic size.

The relative reliability of estimates of net as opposed to gross income should matter. The World Bank's Wealth of Nations project mentioned above might be thought of as a possible candidate data set. However, the World Bank data are not designed for comparing the relative amounts of total wealth held by countries (only the relative shares of different types of wealth are given). Indeed, the World Bank is careful to point this out in their documentation, highlighting the fact that their calculations are not on a PPP basis. ${ }^{24}$ In conclusion, the choice between net and gross income boils down to how much we would like to target net savings now as a conduit to future consumption and confront the difficulty and controversy in doing so. We might well accept that ability to pay should be based on a gross income measure for this purpose. ${ }^{25}$

\section{Conclusion}

It is clear that there are alternative measures of economic size to GDP. Some, for example GNI, merit consideration in future work. Others, such as wealth, do not seem suitable for this purpose. Where we have been able, as seen in the case of the PPP adjustment, we have demonstrated the effect of different measures. We have argued that it is important not just for the measure chosen to be a good indicator of national resources, but that its construction does not depend on too many subjective judgements. Finally, we should repeat that these issues will have to be faced by any operational measure of capability and most measures of economic size can fit our scheme.

\footnotetext{
${ }^{23}$ Some adjustment would also have to be made for obstacles - such as institutional or financial market frictions - to the conversion of potential wealth into actual consumption. Also, the streams should be valued at social prices, and negative externalities would be accounted for as net income losses. The only exception to this, particular to our case, would be all the costs of climate change, which would be kept out of our capability measure as they should be included in the companion responsibility measure, against which capability is measured.

${ }^{24}$ Using a different bottom-up methodology, the authors of 'Sustainability and the Measurement of Wealth' provide estimates but only for a handful of countries. ['Sustainability and the Measurement of Wealth', Arrow, K.J., Dasgupta, P., Goulder, L.H., Mumford, K.J., and Oleson, K., NBER Working Paper No. 16599, 2010.]

${ }^{25}$ Adam Smith's continually endorsed Maxims of Taxation express that a good tax scheme should feature convenience, certainty (and economy) as well as equity. [An Inquiry into the Nature and Causes of the Wealth of Nations, Smith, A., 1776, Book V, Chapter II.] See also footnote 17 on consumption.
} 


\subsection{Income Proportionality and Prosperity Progressiveness}

We now return to what in Section II.1.1 we referred to as the 'homogeneous base capability measure' $\left(B C M_{k}\right)$. When adapting this measure for use in our actual (heterogeneous) world, the fact that some countries are more prosperous ('richer', 'affluent') than others (as reflected in different average income (per capita GDP) levels) is one of the most important features that must be taken into account. Indeed, based on what Adam Rose referred to as 'vertical equity, ${ }^{26}$ it can be argued that capability measures should be prosperity progressive in the sense that a dollar of income of a more prosperous country should be 'taxed higher' than a dollar of a less prosperous one. But how could one achieve this in an acceptable manner?

We have mentioned that the capability measure $\left(B C M_{k}\right)$ for our hypothetical homogeneous world is 'income proportional' $\left(B C M_{n}: B C M_{m}=G D P_{n}: G D P_{m}\right)$. As this was intended to be acceptable in a world where all countries have the same prosperity level, it stands to reason that it should continue to be acceptable for any given group of countries of the same prosperity. In other words, if countries $n$ and $m$ have the same GDP per capita $\left(g d p_{n}=g d p_{m}\right)$, then their capabilities $C_{n}, C_{m}$ should also be proportional to their incomes $\left(C_{n}: C_{m}=G D P_{n}: G D P_{m}\right)$.

This, in turn, might tempt one to reason - on grounds of 'symmetry' as it were - that in a heterogeneous world capability should analogously be proportional in respect of per capita figures, at least for countries with the same income. That is to say, one might be tempted to simply postulate that if two countries $n$ and $m$ have the same GDP, then their capabilities $C_{n}, C_{m}$ should be proportional to their per capita incomes $\left(C_{n}: C_{m}=g d p_{n}: g d p_{m}\right)$.

Adopting this sort of 'prosperity proportionality' requirement would be tantamount to adopting a simple linear prosperity adaptation of the base capability $B C M_{k}$ :

$$
C_{k}=\left(\alpha \times g d p_{k}\right) \times B C M_{k}=\left(\alpha \times g d p_{k}\right) \times G D P_{k} \quad \text { for some constant } \alpha
$$

As it happens, for $\alpha>0$ this modification does lead to (capability-based) cost sharing schemes which can indeed be interpreted as 'progressive' in the sense used for tax regimes (see Box II.2.i). The problem is that there are infinitely many alternative modifications that would also be progressive, and we do not believe that the symmetry argument alluded to above would be sufficient reason for choosing this sort of proportionality option.

To explain this, we need to look at how capabilities would be used in sharing a given cost, say $\Omega$. Keeping in mind the caveats of Section I.2 with regard to involving factors other than capability, a capability-based (Aristotelian) cost-sharing method would distribute $\Omega$ in proportion to countries'

\section{Box II.2.i. Tax Progressiveness: Definitions}

In the context of taxation, three general types of progressiveness are distinguished, namely 'progressive,' 'regressive' and 'flat': if $t(y)$ is the tax payment (in absolute terms), and $y$ the income of a taxpaying individual, then $\tau(y)=t(y) / y$ is the average tax rate (at income $y$ ), and

$$
t(y) \text { is }\left\{\begin{array}{l}
\text { progressive } \text { iff }_{\text {def }} \tau^{\prime}(y)>0 \\
\text { flat iff def } \tau^{\prime}(y)=0 \\
\text { regressive } \operatorname{iff}_{\text {def }} \tau^{\prime}(y)<0
\end{array}\right.
$$

\footnotetext{
${ }^{26}$ Adam Rose, 'Reducing Conflict in Global Warming Policy: The potential of equity as a unifying principle', Energy Policy, December 1990, 4.
} 
relevant capability shares ('Capability Indices') $0 \% \leq C I_{k} \leq 100 \%:{ }^{27}$ that is to say, a country $k$ would be meant to pay $\Omega_{k}={ }_{\text {def }} C I_{k} \times \Omega$.

In order to discuss these capability-based payments in the tax-related terminology introduced in Box II.2.i, we need to look at the implied per capita payment $\left(=\Omega_{k} / P_{k}\right.$ with $P_{k}$ being the population of country $\mathrm{k}$ ), and introduce the relevant capabilities as values of a differentiable function of two variables - namely $G D P_{k}$ and $g d p_{k}\left(=\mathrm{GDP}_{k} / P_{k}\right)$ - such that: $C_{k}=C\left(G D P_{k}, g d p_{k}\right)$. The total capability of the group of countries $\Gamma$ involved in sharing $\Omega$ is then given by:

(2.5) $\quad \Sigma_{\Gamma}={ }_{d e f} \sum_{i \in \Gamma} C\left(G D P_{i}, g d p_{i}\right)$

and $k$ 's percentage share (capability index) is:

$$
C I_{\Gamma}\left(G D P_{k}, g d p_{k}\right)=C\left(G D P_{k}, g d p_{k}\right) / \Sigma_{\Gamma}
$$

Consider then the following simple and intuitive general formula for a (relative) prosperity adjusted capability measure:

$$
C(G D P, g d p)=f(\gamma) \times G D P
$$

with $\gamma$ as 'relative prosperity parameter' given in terms of GDP per capita relative to the world average:

$$
\gamma={ }_{\text {def }} g d p / g d p_{W o r l d} .
$$

The per capita payment, $\left(\Omega_{k} / P_{k}\right)$, conceived as the 'tax payment' (see Box II.2.i) of the average inhabitant can thus be written as: ${ }^{28}$

$$
t\left(G D P_{k}, g d p_{k}\right)=\left[\Omega / \Sigma_{\Gamma}\right] \times f\left(\gamma_{k}\right) \times g d p_{k}
$$

implying a per capita payment rate (= average 'tax rate') of:

$$
\tau_{k}={ }_{\text {def }} t\left(G D P_{k}, g d p_{k}\right) / g d p_{k}=\Omega / \Sigma_{\Gamma} \times f\left(\gamma_{k}\right)
$$

Following the definitions introduced in Box II.2.i, we can hence conclude that a capability measure $C(G D P, g d p)$ of the form defined in (2.7) is:

$$
\left\{\begin{array}{l}
\text { progressive } \text { iff }_{d e f} \mathrm{~d} f / \mathrm{d} g d p>0 \\
\text { flat iff }_{\text {def }} \mathrm{d} f / \mathrm{d} g d p=0 \\
\text { regressive iff } \\
\text { def } \mathrm{d} f / \mathrm{d} g d p<0
\end{array}\right.
$$

In short, any monotonically increasing function $f$ will ensure the prosperity progressivity of capability measures of the form given in (2.7), ${ }^{29}$ and we do not think there are any a priori reasons (such as 'symmetry') to select any one of them. The only way of doing so is to try to use some empirical data on progressivity (of national tax regimes).

${ }^{27} C I_{k}={ }_{\text {def }} C_{k} / \sum_{i} C_{i}$.

${ }^{28} \Omega_{k} / P_{k}=t\left(G D P_{k}, g d p_{k}\right)=\left[\Omega / \Sigma_{\Gamma}\right] \times\left[f\left(\gamma_{k}\right) \times G D P_{k} / g d p_{k}\right] \times G D P_{k}=\left[\Omega / \Sigma_{\Gamma}\right] \times f\left(\gamma_{k}\right) \times g d p_{k}$ where $P_{k}$ is the population of country $\mathrm{k}$.

${ }^{29}$ Which is why (2.4) defined prosperity progressive capability measures for $\alpha>0$ 


\subsection{Gross Capability Measures}

\section{Definition}

Adam Rose gives two examples of implementing vertical equity: at the interpersonal level, he cites progressive income taxation; while at the international level he refers to 'foreign aid by industrialized countries [as a] prime example of vertical equity' ${ }^{30}$ Following the ideas introduced in the preceding section we propose to adapt the Base Capability Measure $B C M_{k}$ (given in 2.1) with an exponential '(power of prosperity) progressivity parameter' $\delta$, by defining the Gross Capability of a country $k$ as:

$$
G C M_{k}^{\delta}=\left(\gamma_{k}\right)^{\delta} \times G D P_{k}^{31}
$$

Note that, since $\mathrm{d} \gamma^{\delta} / \mathrm{d} g d p>0$ if and only if $\delta>0^{32}$ this measure is prosperity progressive for any positive progressivity parameter (as well as income proportional for given levels of prosperity ${ }^{33}$ ).

The key to making gross capability thus conceived operational is the choice of an acceptable progressivity level $\delta$.

One route to calibration is to build on the vertical equity justification for prosperity progression. While the purpose of this paper is not to design a global income tax, most of the ideas used are derived from domestic income tax models, and we believe that the most promising route to determining such a progressivity level is also through the consideration of domestic income tax practices, not least because the sole source of information on preferences for progressivity seems to be the 'shapes' of national income tax systems, which display a measurable degree of liability progression. In Appendix 2, we match our prosperity progressivity parameter $\delta$ with the canonical definition of tax liability progression. We then survey different estimates of countries' tax liability progression and show that these would imply the value of $\delta$ to be positive and less than two. Most of the estimates are clustered in the range between 0.2 and 1 (with higher values mostly confined to one study). ${ }^{34}$

Thus we believe a reasonable value for $\delta$ to be 0.5. This justifies the value we use in the rest of this paper, defining the $\boldsymbol{O}$ fford Gross Capability as:

$$
O G C_{k}=\sqrt{\gamma_{k}} \times G D P_{k}
$$

where $\gamma_{k}=g d p_{k} / g d p_{\text {world }}$ and $g d p=$ per capita GDP. ${ }^{35}$

\footnotetext{
${ }^{30}$ Adam Rose, 'Reducing Conflict in Global Warming Policy: The potential of equity as a unifying principle', Energy Policy, December 1990, 4.

${ }^{31}$ We have tried other formats - such as linear $\left[\left(\lambda \times \gamma_{k}\right)+1\right] \times G D P_{k}$, (satisfying (2.7) - but we found the exponential modification used in (2.12) to be by far the easiest to calibrate (Appendix 2).

${ }^{32} \mathrm{~d} \gamma^{\delta} / \mathrm{d} g d p=g d p_{\text {world }}^{-\delta} \times \delta \times g d p^{(\delta-1)}>0$ iff $\delta>0$.

${ }^{33}$ If $g d p_{n}=g d p_{m}$ then $\gamma_{n}=\gamma_{m}$ and hence $G C M_{n}^{\delta}: G C M_{m}^{\delta}=G D P_{n}: G D P_{m}$ (see section 1.3).

${ }^{34}$ Another justification for progressivity is 'the equal sacrifice principle': that each unit of income given as a contribution should represent the same utility sacrifice for all individuals. Diminishing marginal utility of income is likely therefore to support progressivity in capability. See for example 'The Equal Sacrifice Principle Revisited', Peter J. Lambert and Helen T. Naughton, Working Papers 45, ECINEQ, Society for the Study of Economic Inequality, 2006. Typical values of the degree of inequality aversion used in the climate change debate would imply values of $\delta$ between 0.5 and 1 .

${ }^{35}$ Note: $x^{0.5}=\sqrt{x}$.
} 


\section{Scale and Aggregation Invariance}

The proposed capability measures (and the derived indices) have a number of important (formal) properties that are worth highlighting. For one, their relative proportions are what we call both 'scale' and 'aggregation invariant'.

By scale invariance we simply mean that the relative proportions of the capability measures in question do not depend on the unit of measurement chosen in determining the Base Measure. In other words, the relationship between the capabilities of two countries $k$ and $m$ remains proportionate regardless of whether one chooses, say, dollars $(\$)$ or cents $(\phi)$ to measure the relevant GDPs. It is not difficult to ascertain that it is indeed the case that:

$$
\begin{aligned}
& B C M_{k}[\$]: B C M_{m}[\$]=B C M_{k}[\Phi]: B C M_{m}[\phi] \\
& G C M_{k}^{\delta}[\$]: G C M_{m}^{\delta}[\$]=G C M_{k}^{\delta}[\phi]: G C M_{m}^{\delta}[\mathbb{\phi}]^{36}
\end{aligned}
$$

As concerns aggregation, it is obvious that a country's share of the total capability of a group of countries, as a percentage, depends on the composition of that group - for example, a country's capability percentage is inevitably going to diminish if the group is enlarged. ${ }^{37}$ The point about aggregation invariance is that, by contrast, the relative proportions of these shares are independent of the reference groupings: if the percentage share of a country (relative to the total capability of a group $\Gamma$ ) is $x$-times that of another one, then that relative proportion will hold for any group (containing both of them).

To see this, consider the Gross Capability $G C M_{k}^{\delta}$. If by Gross Capability Index of a country $k$ with respect to a group of countries $\Gamma(k \epsilon \Gamma)$ we mean its percentage share in the sum of gross capabilities of the countries in that group - in other words:

$$
G C I_{k, \Gamma}^{\delta}={ }_{\text {def }} G C M_{k}^{\delta} / \sum_{i \in \Gamma} G C M_{i}^{\delta}[\%]
$$

- it then follows that $G C M_{k}^{\delta}$ is aggregation invariant, because the proportions of these indices remain the same regardless of the reference group $\Gamma$ :

$$
G C I_{n, \Gamma_{1}}^{\delta}: G C I_{m, \Gamma_{1}}^{\delta}=G C I_{n, \Gamma_{2}}^{\delta}: G C I_{m, \Gamma_{2}}^{\delta} \text { (for all } \Gamma_{1}, \Gamma_{2} \text { with } n, m \in \Gamma_{1} \cap \Gamma_{2} \text { ) }
$$

It is easy to see not only that this is indeed the case, but also that these aggregation-invariant proportions are actually the same as the proportions of the relevant gross capabilities themselves, ${ }^{38}$ in other words that:

$$
G C I_{n, \Gamma}^{\delta}: G C I_{m, \Gamma}^{\delta}=G C M_{n}^{\delta}: G C M_{m}^{\delta} \quad \text { (for all } \Gamma \text { with } n, m \in \Gamma \text { ) }
$$

Why is this important? One of the main reasons for objections in the context of (quantity) distributions is a perceived unfair/unjust allocation relative to what that of others: 'It is not fair that I should receive/do $x$-times less/as much than they'. Given this, it would be extremely fortuitous if the proposed equity standard were to be aggregation invariant - in other words, if it did not depend on the particular group of recipients involved - not least because it would avoid the temptation of trying to gain relative advantages through changing the aggregate reference group.

${ }^{36} O G C_{k}^{\delta}[\$]=\left(\gamma_{k}\right)^{\delta} \times G D P_{k}[\$]=\left(\gamma_{k}\right)^{\delta} \times 100^{-1} \times G D P_{k}[\Phi]=100^{-1} \times O G C_{k}^{\delta}[\Phi]$. Note, however, that this would not be the case if one were to compare PPP and market exchange rate figures.

${ }^{37}$ The only exception would be if the additional countries have zero capability, which is impossible for the proposed gross capability measure.

${ }^{38} G C I_{n}^{\delta, \Gamma}: G C I_{m}^{\delta, \Gamma}=\frac{O G C_{n}^{\delta, \Gamma}}{\sum_{i \in \Gamma} O G C_{i}^{\delta}}: \frac{O G C_{m}^{\delta, \Gamma}}{\sum_{i \in \Gamma} O G C_{i}^{\delta}}=O G C_{n}^{\delta}: O G C_{m}^{\delta}$ 
In short, the key feature of our (gross) capacity measures is not their absolute value but their relative proportion. Accordingly we shall not label the relevant axes with numbers, but simply use gridlines to help represent these proportions as the key feature of these measurements.

\section{Payment Rates}

Another characteristic feature worth highlighting is what we referred to earlier (section 1.3) as a 'payment rate'. Assume that the task at hand is to share a certain overall cost, $\Omega$, among the members of a group of countries $\Gamma$, and that this is done in proportion to our capability measures, or rather to the relevant capability indices, namely:

$$
\begin{array}{ll}
B C I_{k}=G D P_{k} / \Sigma_{\Gamma}[\%]\left(\text { with } \Sigma_{\Gamma}={ }_{\text {def }} \sum_{i \epsilon \Gamma} G D P_{i}\right) & (\Gamma-) \text { Base Capability Index } \\
G C I_{k}^{\delta}=G C M_{k}^{\delta} / \Sigma_{\Gamma}^{\delta}[\%]\left(\text { with } \Sigma_{\Gamma}^{\delta}={ }_{\text {def }} \sum_{i \epsilon \Gamma} G C M_{i}^{\delta}\right) & (\Gamma-) \text { Gross Capability Index }
\end{array}
$$

By assumption, country $k$ is meant to shoulder a share $\Omega_{k}$ of this overall cost, which is proportional to its respective capability index. In the case of Base Capabilities, this means: $\Omega_{k}=\Omega \times B C I_{k}$, while the amount for the gross capability distribution is given by $\Omega_{k}^{\delta}=\Omega \times G C I_{k}^{\delta}$. In Section 1.3 , we focused on the per capita payments and their rates, but one may also wish to consider the rates of the absolute payments relative to the absolute 'income', in other words, GDP:

$$
\begin{aligned}
& \omega_{k}={ }_{\text {def }} \Omega_{k} / G D P_{k}=\Omega / \Sigma_{\Gamma} \\
& \text { Base payment rate } \\
& \omega_{k}^{\delta}={ }_{\text {def }} \Omega_{k}^{\delta} / G D P_{k}=\Omega / \Sigma_{\Gamma}^{\delta} \times\left(\gamma_{k}\right)^{\delta} \quad \text { Gross payment rate }
\end{aligned}
$$

The first thing to note is not only that the base rate is a special case of the gross rate $(\delta=0)$, but also that both rates are the same as their per capita versions ${ }^{39}$ (which allows us to ignore the distinction).

In particular, the base payment rate is simply a flat rate corresponding to the overall cost as share of aggregate group GDP. The gross rate, in turn, being identical with the per capita payment rate, is prosperity progressive for $\delta>0 .^{40,41}$

\subsection{Oxford Gross Capability: Some illustrations}

The aim of this section is to graphically illustrate the transition from base to gross capabilities. In order to do this, we need to say a few words about units of measurement. The Base Measure - given by a country's GDP - can be associated with monetary units, such as (purchasing power parity) currency units. In other words, there are certain monetary sums associated with the Base Measure figures.

However, by contracting or expanding these figures (progressively) in order to get our Gross Measure, such an association with actual amounts of money is lost. The adapted GDP figures no longer refer to actual monetary amounts but are 'merely' (dimensionless) numbers, used to fix relative proportions which, as explained above, are not only independent of 'scale', but also of 'aggregation'.

\footnotetext{
${ }^{39}$ See (2.10).

${ }^{40}$ Note, incidentally, that the base rate is simply the limiting case of the gross rate for $\delta=0$.

${ }^{41}$ In this context, it is also worth mentioning that the ratio of gross tax rates of countries $n$ and $m\left(\omega_{n}^{\delta} / \omega_{m}^{\delta}=\right.$ $\left.\left(g d p_{n} / g d p_{m}\right)^{\delta}\right)$ is independent of the amount to be raised $(\Omega)$, which is desirable as it simplifies the determination of the relevant parameters, but is not always the case in tax schemes.
} 


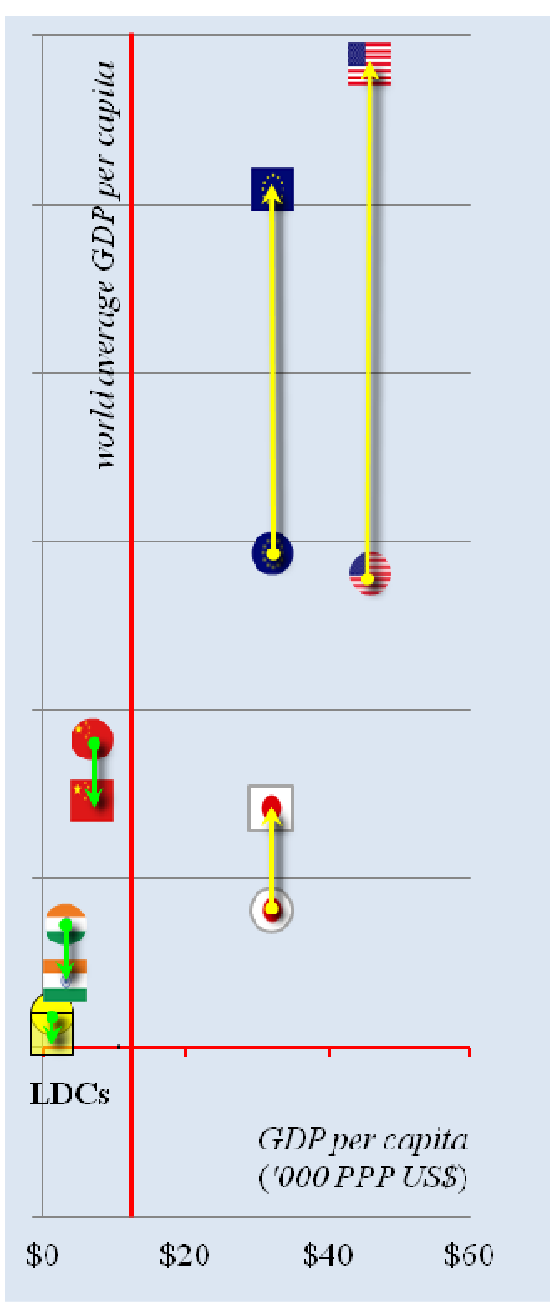

Figure II.1.5.i. Base and Gross Capability: Examples

Figure II.1.5.i depicts the Base and Gross Capabilities of five large economies: India, China, Japan, the EU, and the USA, together with those of the LDCs as a whole. The vertical axis depicts the relevant capabilities (base capability as circles, gross capabilities as squares). The horizontal axis represents GDP per capita in thousands of US\$ (PPP). This figure shows the way in which the base capability (GDP) of countries with per capita GDP more/less than the world average of $\$ 10,643$ (the vertical red line) gets magnified (yellow arrows)/contracted (green arrows) in the transition to gross capabilities. US Base Capability is shown to roughly double (+100 per cent); the EU and Japan following, each with a three-quarter addition (+74 per cent); China a one-fifth contraction ( -20 per cent); and India just under halving its Base Capability ( -45 per cent). It is seen that countries with (roughly) the same per capita GDP - such as the EU and Japan - will have the same level of progressive magnification/contraction, the degree of which is in proportion to the distance from world average GDP per capita.

The extent of this progressive contraction or magnification is dependent on the progressivity parameter $(\delta)$, chosen here to be 0.5 (see section 1.4). Figure II.1.5.ii plots the values of transformation parameter $(\gamma)^{\delta}$ as a function of the progressivity parameter $\delta$ for the above five economies (given their relative prosperity factors $\gamma_{k}$ ) to illustrate the sensitivity of these prosperity transformations with regards to the choice of $\delta$. In light of the fact that $\left(\gamma_{k}\right)^{\delta}=$ $O G C_{k}^{\delta}: G D P_{k},-$ see equation (2.12) - it is on the one hand easy to see that for $\delta=0$ there is no progressivity, ${ }^{42}$ gross capability simply equals base capability (in other words, GDP). On the other hand, since $\left(\gamma_{k}\right)^{1}=\gamma_{k}$, the degree of the transformation at $\delta=1$ is simply the relevant ratio of the per capita GDP to the world average.

Another way of illustrating the nature of this progressivity transformation is to make use of the fact that gross capability can be written as a function $-O G C_{k}^{\delta}\left(G D P_{k}, P_{k}\right)$ - of two independent variables: base capability $\left(B C_{k}=G D P_{k}\right)$ and population size $\left(P_{k}\right) \cdot{ }^{43}$ Moreover, the graphical representation can further be simplified by 'factoring in' population size, in the sense of turning to the relevant per capita measures. If $b c_{k}={ }_{d e f} B C_{k} / P_{k}$ is the per capita base capability of country $k$, and $o g c_{k}^{\delta}={ }_{\text {def }} O G C_{k}^{\delta} / P_{k}$ its per capita gross capability, then we have:

$$
\text { (i) } \quad b c_{k}=g d p_{k} \text {; }
$$

$$
\operatorname{ogc}_{k}^{\delta}\left(b c_{k}\right)=g d p_{\text {world }}{ }^{-\delta} \times\left(b c_{k}\right)^{\delta+1} .^{44}
$$

\footnotetext{
${ }^{42}\left(\gamma_{k}\right)^{0} \equiv 1$, implying a flat payment rate $\mathrm{d} \omega_{k}^{0} / \mathrm{d} g d p=0$.

${ }^{43} O G C_{k}^{\delta}={ }_{\text {def }}\left(\gamma_{k}\right)^{\delta} \times G D P_{k}=\left(g d p_{k} / g d p_{\text {world }}\right)^{\delta} \times G D P_{k}, g d p_{k}==_{\text {def }} G D P_{k} / P_{k}$

${ }^{44} o g c_{k}^{\delta}=\left(g d p_{k} / g d p_{\text {world }}\right)^{\delta} \times g d p_{k}=\left(g d p_{k}\right)^{\delta+1} / g d p_{\text {world }}{ }^{\delta}=g d p_{\text {world }}{ }^{-\delta} \times\left(b c_{k}\right)^{\delta+1}$
} 


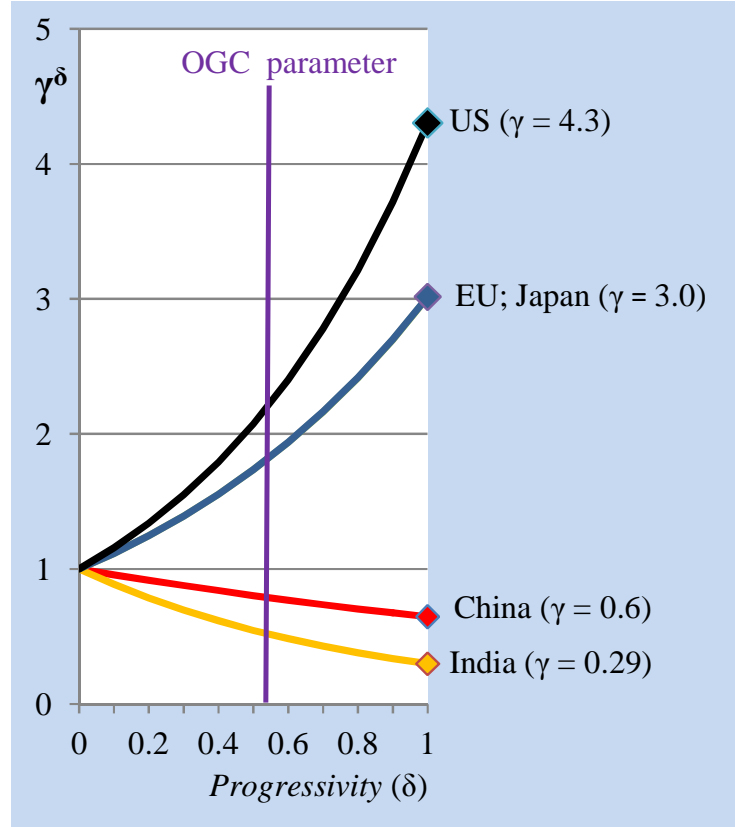

Figure II.1.5.ii.

Gross Capability Sensitivity to Progressivity

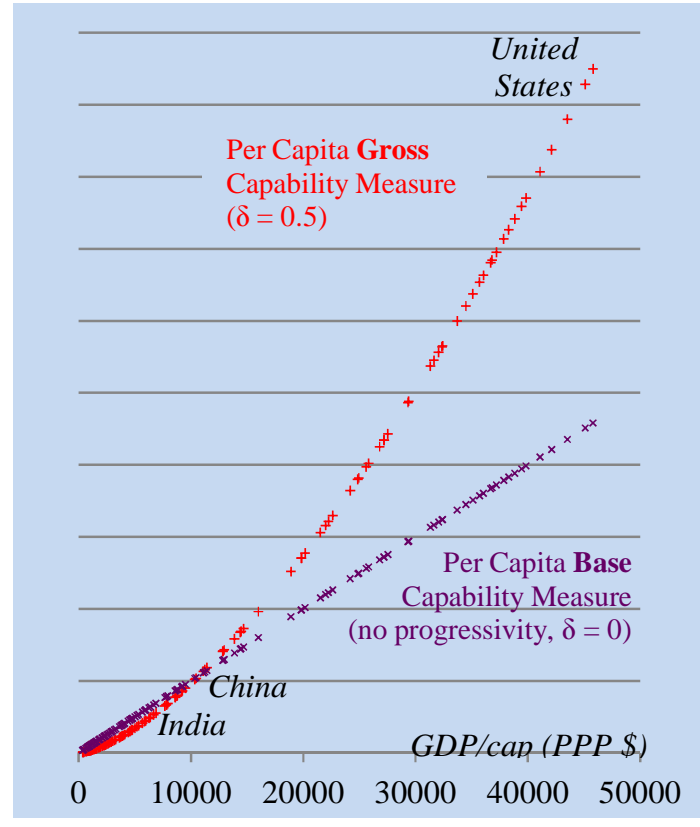

Figure II.1.5.iii.

Per Capita Measures

Figure II.1.5.iii is a scatter diagram illustrating of the actual values for per capita base and gross capabilities of various countries, clearly displaying the progressiveness of the transformation from the former to the latter. 


\section{Net Capabilities: Poverty Allowances And Poverty AdJUSTED CAPABILITy}

Having introduced a progressive measure of a country's 'gross capability (to pay)', we now turn to the idea of 'capability allowances' as deductions from gross capabilities. The key feature of these subtractive adjustments (based on allowances) is that - unlike multiplicative progressivity adjustments ${ }^{45}$ - they can leave a country with zero net capability (or even negative capability). This is akin to the income tax case where basic allowances for each tax payer are meant to reduce to zero the tax liability of a person earning less than that basic amount.

What sort of features should be significant in this context? What features should be allowed to potentially reduce to zero a country's capability to pay? One might be tempted to have one's particular national circumstances included in that category, but to avoid interminable 'fairness disputes', it may be more fruitful to take another leaf from the income tax practice book, where there seems to be widespread agreement that, by and large, only poor people (or people with very low incomes) should be exempt from income tax through the issuance of basic allowances.

As a matter of fact, there can be little doubt that poverty has to be a salient feature regarding a country's capability to pay (for climate change costs). At Rio+20, the international community acknowledged yet again that 'eradicating poverty is the greatest global challenge facing the world today and an indispensable requirement for sustainable development. In this regard we are committed to free humanity from extreme poverty and hunger as a matter of urgency. ${ }^{46,47}$ Although there may be other features that could arguably be treated in this way, we shall, for the present purposes, confine ourselves to such poverty capability allowances and adjustments.

\subsection{The Size of Poverty, Poverty Allowances \& Poverty Adjustments}

The most significant, and probably the only universally acceptable, feature to be reflected in a country's capability through the issuance of capability allowances is thus, in our view, the size of its poverty problem. How can this be quantified for the purpose of providing capability allowances? Recognizing that it is not easy to define who is to count as being poor, we are nonetheless convinced that the idea of adjusting a country's capability in order to reflect its poverty problem cannot be adequately done without of some form of poverty headcount.

We therefore introduce Poverty Capability Adjustments $\left(P C A_{k}\right)$ which are meant to be proportional to the size of a country's poverty problem, which in turn we believe must be based on a poverty headcount, $P H_{k}$, (or $P H_{k}^{\Phi}$ : the number of poor people as defined by methodology $\Phi$ ).

Accordingly, we believe that the relevant adjustments should be carried out on the basis of issuing person-based poverty capability allowances $(\Pi)$ in proportion to the number of poor people living in the country:

$$
P C A_{k}=P H_{k} \times \Pi
$$

${ }^{45}$ Under the multiplicative progressiveness adjustment, zero capability is only possible with zero income: $O G C_{k}^{\delta}=\left(\gamma_{k}\right)^{\delta} \times G D P_{k}=0$ iff $G D P_{k}=0$.

${ }^{46}$ The Future We Want; I. Our Common Vision, para. 2;

www.un.org/disabilities/documents/rio20_outcome_document_complete.pdf

${ }^{47}$ It might also be relevant that countries with a large share of their population in poverty cannot remove them from that condition immediately and are constrained to provide continual relief. Martin Ravallion demonstrates that internal tax redistribution cannot alleviate poverty when, among other things, the percentage of the poor (measured for example by those earning less than $\$ 2$ a day) is too high. ['Do Poorer Countries Have Less Capacity for Redistribution?', Ravallion, M., Journal of Globalization and Development, Berkeley Electronic Press, 2010, vol. 1(2), 1.] 
It is important to highlight two things in this context. First, this poverty capability allowance $\Pi-$ even though allocated per (poor) person, per year - has nothing to do with individual incomes, of poor or rich people, aspired or normative. It is a conversion and calibrating parameter which transforms a headcount into a number to be subtracted from our gross capability figure, in order to adjust it to match the country's poverty problem. (The calibration of the appropriate level of $\Pi$ is carried out in Appendix 3.)

Second, the number of poor people on its own may not be fully adequate to reflect the size of a country's poverty (problem) in this context, which is why one might wish to augment the calculation of the poverty capability adjustment with a poverty intensity index, $P I I_{k}\left(P I I_{k}^{\Phi}\right.$ as defined by methodology $\Phi)$.

A country's poverty capability adjustment $P C A_{k}$ then becomes the product of: a measure of the 'depth' of its poverty problem (poverty intensity) represented by $P I I_{k}$, a measure of its 'breadth' (poverty headcount) represented by $P H_{k}$, and the general conversion parameter $\Pi$ :

$$
P C A_{k}=P I I_{k} \times P H_{k} \times \Pi \text {. }
$$

\subsection{The Multidimensional Poverty Index}

Poverty has traditionally been defined in terms of personal income. To be precise, being poor was defined in terms of earning less than a certain income, say $\$ 2$ per day, 'but the traditional narrow focus on income as the only measure of a person's wellbeing, or lack of it, is being increasingly challenged. ... The human development approach has long argued that although income is important, it has limitations that call for more direct measures. ... In its 20th anniversary year, the UNDP Human Development Report decided to introduce a new international measure of poverty - the Multidimensional Poverty Index or MPI - which directly measures the combination of deprivations that each household experiences. The MPI uses microeconomic data to reflect the percentage of households that experience overlapping deprivations in three dimensions - education, health and living conditions. The new MPI was developed by the Oxford Poverty and Human Development Initiative $^{48}$ with UNDP support and supplants [their 1997 Human Poverty Index]. ${ }^{49}$

The Multidimensional Poverty Index $\left(M P I_{k}\right)^{50}$ is the product of two factors, namely (i) the proportion of poor people (within a given population), referred to as the 'multidimensional headcount ratio' $\left(h_{k}\right)$, and (ii) the 'intensity (or breadth) of poverty' $\left(a_{k}\right)$ :

$$
M P I_{k}=h_{k} \times a_{k}
$$

with $h_{k}=P H_{k}^{M P I} / P_{k}$ (where $P H_{k}^{M P I}$ is the number of MPI-poor, and $P_{k}$ the total size of the population, respectively), and $a_{k}=c_{k} / P H_{k}^{M P I}$ (where $c_{k}$ is the total 'deprivation score' of the relevant poor population, see below). ${ }^{51}$ Thus:

$$
M P I_{k}=h_{k} \times a_{k}=c_{k} / P_{k}
$$

\footnotetext{
48 Oxford Poverty and Human Development Initiative (OPHDI) is an economic research centre within the Oxford Department of International Development at the University of Oxford.

${ }^{49}$ See 'Multidimensional Poverty: Measurement, Estimation, and Inference', Bennett C.J. and Mitra, S., Econometric Reviews, Vol. 32(1), 2012; and also the website for the Oxford Poverty and Human Development Initiative www.ophi.org.uk/policy/multidimensional-poverty-index/background/.

${ }^{50}$ The formalism in this section is based on that used by OPHDI. We used a normalized set of the MPI index values to obtain an intensity of poverty that is, on average, 1 across countries.

${ }^{51}$ The 'intensity of poverty', in other words, is simply the country's deprivation score per (poor) capita.
} 
Each person $i$ is assigned a deprivation score $c_{i}$ according to his or her deprivations in the component indicators. The deprivation score of each person is calculated by taking a weighted sum of the number of deprivations experienced, so that the deprivation score for each person lies between 0 and 1 . The score increases as the number of deprivations of the person increases, reaching its maximum of 1 when the person is deprived in all indicators. A person who is not deprived in any indicator receives a score of 0 . Thus:

$$
c_{i}=\sum_{m=1}^{d} w_{m}^{i} I_{m}^{i} \quad \text { gives } i \text { 's deprivation score, }
$$

where $I_{m}^{i}$ is the (binary) indicator of presence $\left(I_{m}^{i}=1\right)$ or absence $\left(I_{m}^{i}=0\right)$ of household deprivation $m$ and $w_{m}^{i}$ being the weight attached to deprivation .

\subsection{The Oxford Capability Measure and Index}

Although the Oxford Measure and the MPI were conceived independently, it is obvious that the two match perfectly, and that the MPI multidimensional headcount ratio $h$ and its intensity of poverty index $a$ can thus be used to operationalize our poverty headcount measure $P H_{k}$ and our poverty intensity measure $P I_{k}$, respectively:

$$
P H_{k}^{\mathrm{MPI}}={ }_{\text {def }} P_{k} \times h_{k} \text { and } P I I_{k}^{\mathrm{MPI}}={ }_{\text {def }} a_{k}
$$

The MPI-based poverty capability adjustment is consequently given by:

$$
P C A_{k}^{M P I}=\Pi \times\left(P_{k} \times h_{k}\right) \times a_{k}=\Pi \times P_{k} \times\left(h_{k} \times a_{k}\right)=\Pi \times P_{k} \times M P I_{k}
$$

Deducting this adjustment from the Oxford Gross Capability measure $O G C_{k}=\sqrt{\gamma_{k}} \times G D P_{k}$ defines the Oxford Capability Measure:

$$
O C M_{k}=O G C_{k}-P C A_{k}^{M P I}=\sqrt{\gamma_{k}} \times G D P_{k}-\Pi \times P_{k} \times M P I_{k} .
$$

The OCM is an absolute measure of a country's capability to pay (for climate change activities). It can be negative, indicating a 'capability headroom', in the same way in which the difference between gross income and basic tax allowance can be negative, and as such, indicating 'income tax liability headroom'.

In Section II.1.5 we illustrated the progressive transition from our Base to the Gross Capability Measure in terms of five large economies (together with the LDCs as a whole), and here we do the same for the transition from the gross to the net measure. Figure II.2.3.i replicates the original transition from base- (circles) to gross-capabilities (squares), and then depicts the net changes, due to the poverty adjustments, from gross to the Oxford measure (diamonds). Not surprisingly, there are no such adjustments for the three rich economies. China's capability contraction due to these poverty adjustments is relatively small (an additional 5 base capability percentage points, see Table II.2.3.i), while India and the LDCs have significant additional reductions of 56 and 136 percentage points, respectively leaving India 1, and the LDCs 67 percentage points below zero capability. 

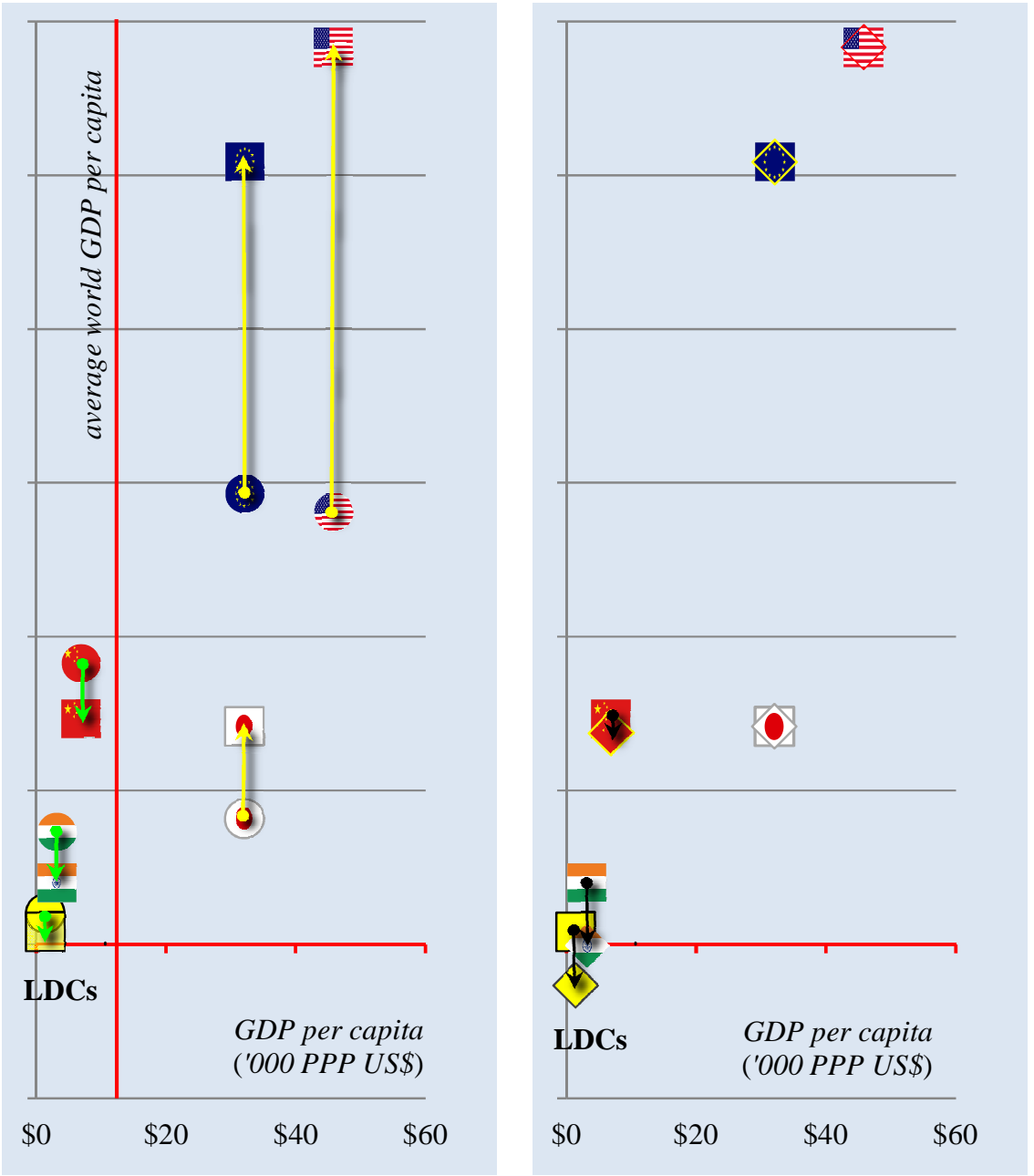

Figure II.2.3.i. The transition from Gross to Oxford (Net-) Capability

$\begin{array}{lll} & \text { Gross } & \text { Net } \\ \text { US } & 107 \% & 107 \% \\ \text { Japan } & 74 \% & 74 \% \\ \text { EU } & 74 \% & 74 \% \\ \text { China } & -20 \% & -25 \% \\ \text { India } & -45 \% & -101 \% \\ \text { LDCs } & -31 \% & -167 \%\end{array}$

Table II.2.3.i Magnification (+) and contraction (-), relative to Base Capability (GDP)

In defining a fair share of a given burden/cost numerically, we introduce a burden sharing index based on the relevant positive capability measures:

(2.31) $O C I_{k}=O C M_{k}^{+} / O C M_{W o r l d}^{+}($Oxford Capability Index $)$ 
with $O C M_{k}^{+}=\max \left(O C M_{k}, 0\right)$, and $O C M_{W o r l d}^{+}=\sum O C M_{k}^{+}$. This index defines the fair share of a total given (economic) cost that a country could be asked to shoulder on the basis of its capability to pay, as measured by the Oxford Capability Measure.

An important aspect of the Oxford approach which should be highlighted at this point is that - unlike the 'Green Development Rights' approach which is discussed in Part III - the Oxford model does not require information about individual incomes and their distribution. It applies the income tax concept at the country level. The above-mentioned person-based allowances, in particular, are used to determine adjustments to $\boldsymbol{a}$ country's (gross) capability, ${ }^{52}$ allowing it to fulfil its domestic obligations towards its poor, obligations that, as such, supersede its international obligations to share the climate change burden. They are not inextricably tied to any assumptions about 'poverty line' income levels. All they require is a poverty headcount, and a consensus on how much of a country's gross capability should be exempted from counting towards its international climate change obligations for each poor inhabitant.

${ }^{52}$ They are, in particular, not allowances made with the intention of exempting poor individuals from having their income counting towards international obligations. 


\section{The Greenhouse Development Rights (GDR) Approaches ${ }^{53}$}

\section{THE GDR FRAMEWORK}

The best-known, and possibly only, numerical operationalization of the UNFCCC concept of 'respective capabilities' is the Capacity Indicator (CI) developed in the 'Greenhouse Development Rights' framework; it ranges from 0 to 100 per cent.

What is it used for? The GDR CI is used to allocate national obligations. It is seen to represent the 'national shares of the global mitigation and adaptation burden in a manner that ... is truly consistent with the UNFCCC's broad principle of "common but differentiated responsibilities and respective capabilities".' $[2: 35]^{54}$

Why 'development rights'? The GDR framework is based on the concept of a development threshold which initially (see [1]) reflected 'a level of socio-economic development to which all countries are entitled. This threshold would be measured by a "capacity indicator" that would include but not necessarily be limited to per capita income. ${ }^{, 55}[1: 7-8]$ As a country threshold, it was used to distinguish between two types of countries, namely 'Annex North' and 'Annex South':

'Those countries whose capacity indicator exceeds the development threshold (let's call these "Annex North" countries) would collectively be obligated to pay for the low-carbon development needed to meet the global mitigation shortfall. The allocation of this burden within Annex North would, in turn, be based on national responsibility and capacity indicators - countries with greater responsibility and capacity would be obligated to pay to mitigate a correspondingly larger proportion of the global mitigation shortfall.

$\cdots$

Those countries whose capacity indicator falls below the development threshold ("Annex South") would not be required to contribute to meeting the global mitigation shortfall. Instead, they would be required, in proportion to their obligation indicator, to allocate resources directly to human development.' [1:8]

It is not entirely clear how the intra-Annex South allocation of resources in proportion to the obligation indicator was meant to have worked ${ }^{56}$ - which may be one of the reasons why the Annex North/Annex South distinction was subsequently dropped from the GDR framework. What is

\footnotetext{
${ }^{53}$ Source Documents:

[1] Paul Baer, Tom Athanasiou, and Sivan Kartha, Greenhouse Development Rights: An approach to the global climate regime that takes climate protection seriously while also preserving the right to human development, EcoEquity and Christian Aid, November, 2006.

[2] Paul Baer, Tom Athanasiou, and Sivan Kartha, The Right to Development in a Climate Constrained World: The Greenhouse Development Rights Framework, Vol.1, Publication Series on Ecology, Heinrich Böll Foundation, Berlin, November 2007.

www.boell.de/downloads/The_Right_to_Development_in_a_climate_contrained_World_gdr_klein_en.pdf

[3] The Greenhouse Development Rights Framework (2008), The right to development in a climate constrained world, Second Edition.

http://gdrights.org/wp-content/uploads/2009/01/thegdrsframework.pdf.

${ }_{55}^{54}[n, y]=$ Page $y$, in source document $n$ (given in previous footnote).

55 A footnote mentions that 'Some people in the GDRs coalition are thus arguing for an indicative definition of the development threshold that is based entirely on the Human Development Index or other more directly qualitative indicators.', [1:10]

${ }^{56}$ Judging from the statement that 'as long as China as a whole remained below the development threshold, it would be obligated not to mitigation activities, but rather to activities designed to promote the human development of its own people' [1:8], it appears that the allocation of resources is meant to be domestic, but then it is not clear how these payments should be proportional to the countries' obligation indicator.
} 
absolutely clear is that the country 'obligation' shares are designed to take into account 'intra-national disparities' [1:8], indeed 'intra-national inequity'. [1:7]

This remained true even after the North-South country distinction had been dropped. While the country development threshold of the initial framework was turned into a development threshold for individual people, the key idea behind the GDR methodology of defining (fair) burden shares for countries is the idea that "the "global middle class," which has reached a level of consumption that yields an appreciable contribution to the climate problem, and has similarly acquired enough capacity to help bear the costs of managing that problem.' [2:27] The aim of the GDR approach is to put an end to what is sometimes described as the rich hiding behind the poor in developing countries. ${ }^{57}$

The shift from GDR Mark 1 to GDR Mark 2 does not just abolish a North-South distinction between countries, it essentially abolishes 'countries' in favour of 'global individuals' without reference to the national circumstances in which they live. ${ }^{58}$

'Thus, we stress that it should be poor individuals, not poor nations, who are excused from bearing climate-related obligations. Individuals with incomes above the development threshold-even if they live in countries with average incomes below the threshold - should be accountable for their fair share of the global climate burden. Similarly, national obligations should be reckoned in accordance with the obligations of their individual inhabitants. '[2:29]

Whereas in GDR-1, the rich in poor countries were meant to be obliged to pay for the development of the poor (in their country), in GDR-2, people who live below the (person-based) development threshold are exempted from having to pay. The two are, of course, not quite the same, and one may wonder in what sense the latter remains a 'development right'. While the 'right to develop' under the GDR-1 framework was what has become known as a 'claim right', implying the existence of a corresponding duty/obligation on someone (namely the rich of the country in question), under GDR-2 this seems to have transformed into a liberty/privilege of the poor not being obliged to pay. ${ }^{59}$

\section{THE GDR CAPACITY INDICATOR}

As already mentioned, the GDR-2 Capacity Indicator (CI) is defined in terms of a person-based development threshold $(\tau)$ intended to reflect the 'right to a modest but dignified level of well-being. ... Below this threshold, individuals must be allowed to prioritize development'. ${ }^{600]}$ 'This means that they should not have to help bear the burdens of dealing with the changing climate, on either the mitigation or the adaptation sides. Those above the threshold, on the other hand, must help to shoulder these burdens, and this regardless of whether they happen to live in the North or in the South'.[2:27]

The threshold is used to divide people into two categories - say for simplicity's sake: the 'poor', and the 'rich' - depending on whether the personal income is below or above the threshold. The indicator, in turn, is given by (the relative proportions of) a country's 'Capable Incomes' (CapInc), which is the sum of the income shares greater than the development threshold of all the country's rich inhabitants:

$$
\operatorname{CapInc}_{k}^{\tau}=\sum_{p \in k: y_{p} \geq \tau}\left(y_{p}-\tau\right)
$$

\footnotetext{
57 'India's rich can hide not only behind the North's rich, but behind India's poor as well.' [2:66]

58 'Crucially, we reckon the development threshold as an individual, not national average, threshold.' [2:28]

${ }^{59}$ For more on these rights taxonomy, see: see http://plato.stanford.edu/entries/rights/\#2.1.

${ }^{60}$ Note: this clearly indicates that the 'right to development' is here taken to be a personal liberty/privilege type of right.
} 
with $y_{p}$ the income of person $p$ in country $k .^{61}$

Figure III.2.i provides a graphic representation of these concepts for two hypothetical countries 'A' and 'B'. The horizontal axis represents the population and the total area under the curves (the sum of the respective red and green areas) their national income (GDP).

The threshold is based on the concept that "a "dignified level of human development free from the privations of poverty" implies a line higher than a "poverty line," that it indeed implies something like 150 percent of a poverty-line income'. This raises the question as to what exactly a 'poverty-line income' is meant to be. The authors are quite adamant 'that it is not the typical figures of $\$ 1$ per day or $\$ 2$ per day ... It is more like $\$ 16$ a day, or, equivalently, $\$ 6000$ a year', thus resulting in an annual development threshold $\tau$ of $\$ 9000$.

\begin{tabular}{|c|c|c|c|c|c|c|c|}
\hline \multicolumn{8}{|c|}{ Table III.2.i. GDR-2 'Country Statistics’ (I) } \\
\hline Country & pop. & poor & GDP & GDP/cap & $D N$ & CapInc & $\boldsymbol{C \boldsymbol { I } ^ { \dagger }}$ \\
\hline A & 100 & 54 & $\$ 986 \mathrm{k}$ & $\$ 10 \mathrm{k}$ & $\$ 243 k$ & $\$ 329 k$ & $82 \%$ \\
\hline B & 50 & 34 & $\$ 346 \mathrm{k}$ & $\$ 7 \mathrm{k}$ & $\$ 175 \mathrm{k}$ & $\$ 71 \mathrm{k}$ & $18 \%$ \\
\hline
\end{tabular}

The GDR-2 Capacity Indicator $C I_{k}$ is then given by the proportions of the 'capable' parts of GDP $\left(\right.$ CapInc $_{k}^{\$ 9000}$ ) - those above the development threshold, as represented by the red areas in Figure III.2.i:

$$
\operatorname{CI}_{k}=\operatorname{CapInc}_{k}^{\$ 9000} / \sum_{n} \operatorname{CapInc}_{n}^{\$ 9000}
$$

This means, in particular, that in a world comprised only of our two hypothetical countries (see Figure III.2.i) Country A would have to shoulder 82 per cent, and country B 18 per cent of the common burden (see Table III.2.i).

Interestingly, the exposition of the GDR account in [2] also refers to 'the income needed to raise the poorer part of the population to the development threshold' referring to its sum-total as the country's 'development need' ${ }^{62}$ (the yellow areas in Figure III.2.i, designated as $D N_{k}$ ). The reason why this is of particular interest is that while capturing this development need in a capability measure is implied as being 'critical' ${ }^{63}$ it does not actually enter into the GDR-2 capacity indicator formula, which is defined exclusively in terms of the income 'surplus' (over and above the development threshold) of the global rich.

\footnotetext{
${ }^{61}$ In practice, these figures are calculated by distributing the national income figures of countries - their (income) GDP - using a log-normal distribution parameterized by the per capita GDP and the relevant Gini coefficients. See Appendix B: GDRs calculations [2:74-78].

$62[2: 36]$

63 'Also, it is important to note that capacity and responsibility are defined in individual terms, in a manner that takes explicit account of the distribution of income and emissions - inequality - within countries. This is critical. Relying merely on national per capita averages would fail to capture either the true depth of the development need or the actual extent of the national wealth.' [2:11]
} 

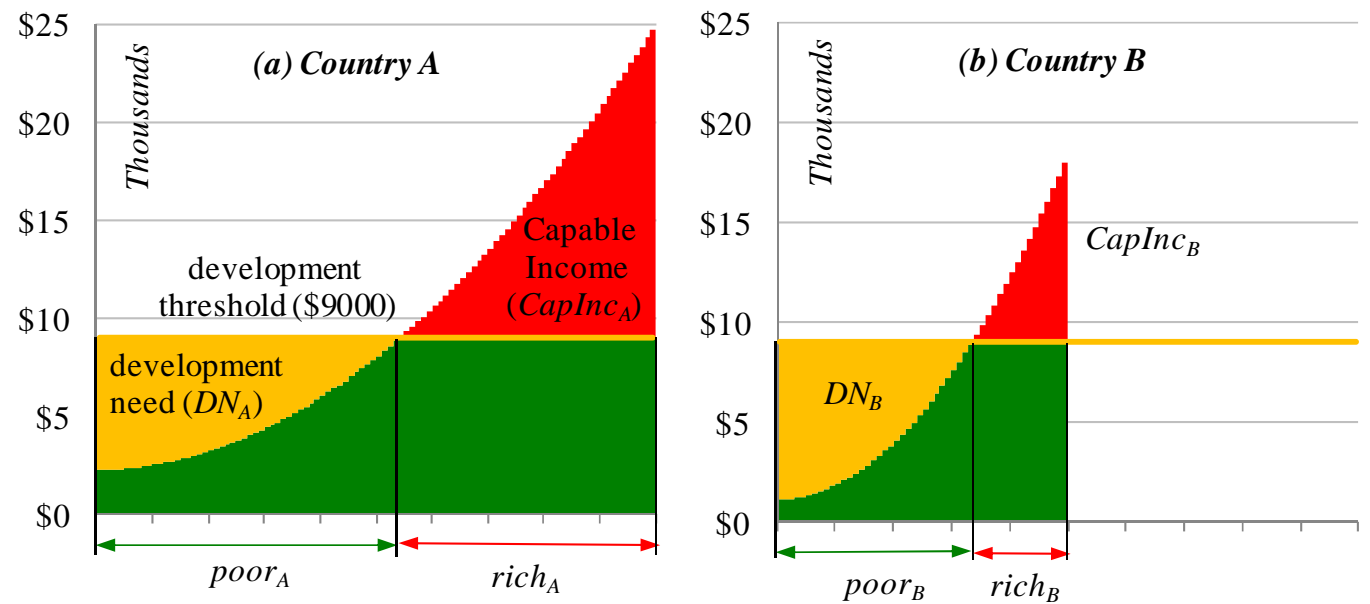

Figure III.2.i. The GDR Framework: Development Needs and Capable Incomes
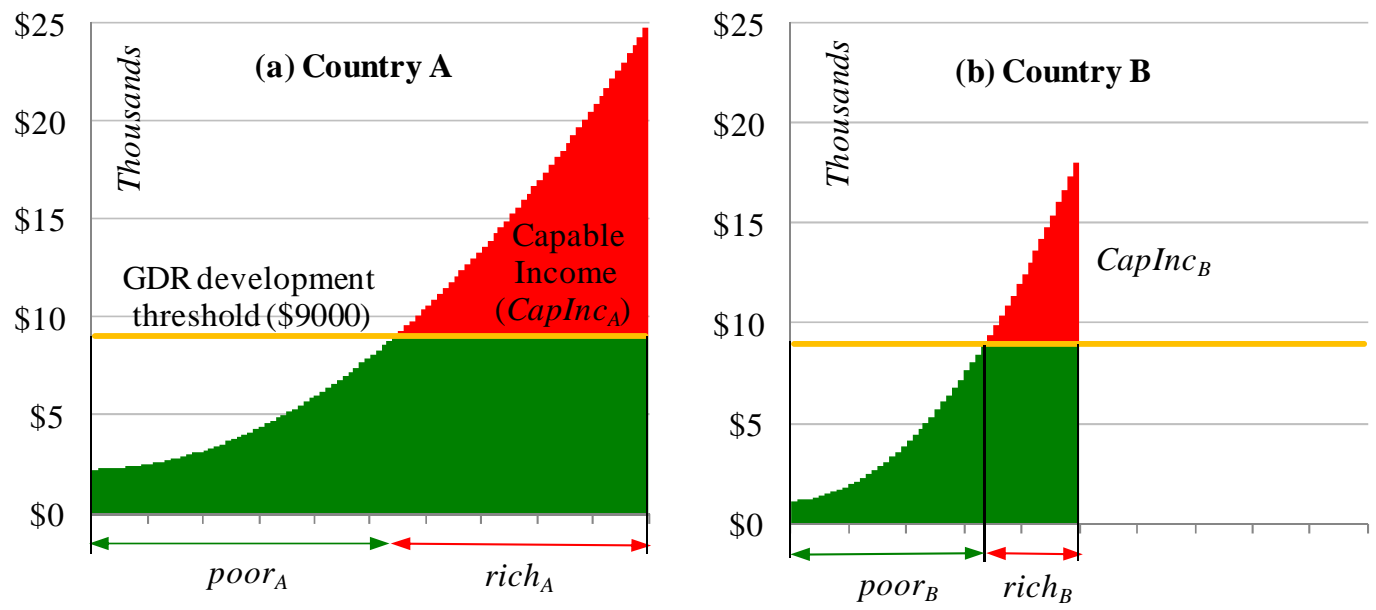

\begin{tabular}{|c|c|c|c|}
\hline $\begin{array}{l}\text { Tab } \\
\text { Stat }\end{array}$ & $\begin{array}{l}\text { III.2.ii. G } \\
\text { 'ics' (II) }\end{array}$ & R-2 'Cou & \\
\hline & pop. & poor & GDP \\
\hline $\boldsymbol{A}$ & 100 & 54 & $\$ 986 \mathrm{k}$ \\
\hline$B$ & 50 & 34 & $\$ 346 \mathrm{k}$ \\
\hline$B^{*}$ & 84 & 68 & $\$ 477 \mathrm{k}$ \\
\hline & GDP/cap & CapInc & $C I$ \\
\hline$A$ & $\$ 10 \mathrm{k}$ & $\$ 329 k$ & $82 \%$ \\
\hline$B$ & $\$ 7 \mathrm{k}$ & $\$ 71 \mathrm{k}$ & $18 \%{ }^{\#}$ \\
\hline$B^{*}$ & $\$ 6 \mathrm{k}$ & $\$ 71 \mathrm{k}$ & $18 \%{ }^{\dagger}$ \\
\hline & & $\begin{array}{l}\text { ve to } C a \\
\text { e to } C a p\end{array}$ & $\begin{array}{l}{ }_{1}+\text { CapIn } \\
+ \text { +CapInc }\end{array}$ \\
\hline
\end{tabular}

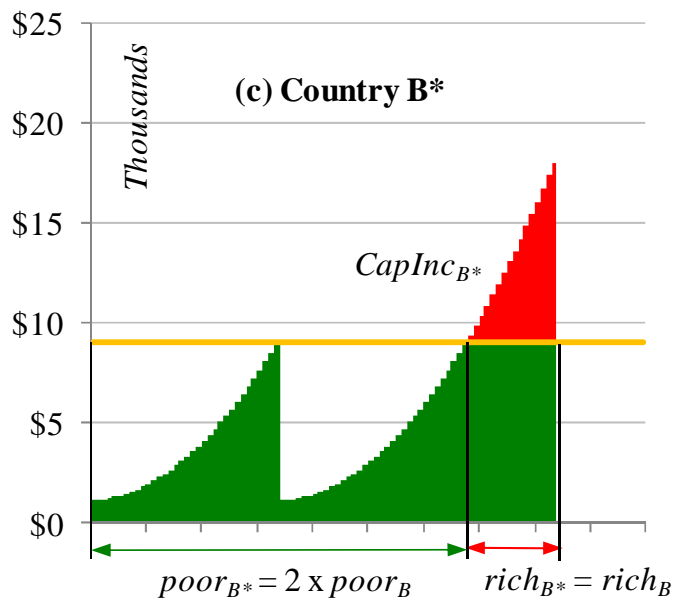

Figure \& Table III.2.ii. GDR-2 Poverty Size Insensitivity \& GDR-2 ‘Country Statistics’ (II)

The need to take into account such 'development needs' - or, rather the need for a country to be able to comply with its domestic obligations to address poverty - is, of course, one of the key elements in the Oxford approach. In our view the most serious shortcoming of the GDR-2 framework is its lack of 
sensitivity to the size of the poverty problem in countries, as reflected, say, in the size of their poor population (their 'poverty headcount', see Section II.2.1).

As mentioned above, the GDR Capacity Indicator $\left(C I_{k}\right)$ is determined exclusively by the income surplus (over and above the chosen development threshold) of the rich residents. It is completely impervious to the number of poor there are in the country. Figure III.2.ii introduces another hypothetical country, Country $\mathrm{B}^{*}$, as an alternative to Country B, with exactly the same rich population as Country B, but with twice the number of poor (more precisely, the poor in $\mathrm{B}^{*}$ are those of B with an additional 'clone'). While this does make a difference in the overall prosperity of the two countries, as measured in GDP per capita (see Table III.2.ii) it obviously has no effect on the income surplus by the rich - the countries' capable incomes (CapInc) represented by the red areas in Figure III.2.ii.b $\left(\operatorname{CapInc}_{B}\right)$ and Figure III.2.ii.c $\left(\operatorname{CapInc}_{B^{*}}\right)$, are both at $\$ 71,000$, implying that they would have to take on the same share of a climate change burden.

\section{From National Development Claim Rights to Global Rich Obligations}

The focus on the 'global rich' or, to be more precise, on preventing the 'global middle class' - defined in terms of having an income above the globally fixed development threshold (\$9000) - from 'hiding behind the poor' (see Section III.1) has, it seems, been one of the key objectives of the GDR project, and has been embraced in both versions of the framework, as illustrated by the following two quotations:

(GDR-1) The point is that a nation's wealthy minority must be properly accounted in the calculation of its responsibility and capacity, even if the majority of its people are quite poor or even utterly impoverished. $^{64}$

(GDR-2) Thus, we stress that it should be poor individuals, not poor nations, who are excused from bearing climate-related obligations. Individuals with incomes above the development threshold - even if they live in countries with average incomes below the threshold - should be accountable for their fair share of the global climate burden. ${ }^{65}$

The other key tenet of the GDR project has been that that the global poor - those earning less than the development threshold - should have the right to develop. What has changed from the first to the second version is that, while GDR-1 still had substantive references to country characteristics - in particular, in its differentiation between 'Annex North' and 'Annex South' - GDR-2 treats individuals, rich or poor, as completely devoid of their national contexts and circumstances. ${ }^{66}$ This reflects a fundamental philosophical difference between the GDR and the Oxford approaches, although these two approaches are in origin actually quite similar and with the aim of establishing a metric for fair burden sharing, based on a taxation analogy. ${ }^{67}$

As mentioned in Section III.1, the development rights of the poor in Annex South countries in the original (GDR-1) version of the GDR framework were actually a form of 'claim right' with a corresponding obligation on their national government/the rich of their country. In the transition to the GDR-2 version, this right - not surprisingly given the 'globalization' of the context - turned into an

\footnotetext{
${ }^{64}$ [1:7], emphasis added.

65 [2:29]

66 'Similarly, national obligations should be reckoned in accordance with the obligations of their individual inhabitants. This, in a world of nations, is the only reasonable approach to the problem here.' [2:29]

67 'All in all, this approximation of capacity is a somewhat crude but still defensible representation of the national income that could legitimately be "taxed" to help shoulder the climate burden.'[2:36]
} 
'exemption right', in other words a privilege to be exempted from what can be regarded as a global climate tax regime.

By contrast, the incomes of the resident 'global rich', as mentioned earlier, are to be taken into account in determining the share of this global tax which national governments are expected, in fairness, to pay. The only function of national governments with respect to the GDR-2 framework is, as it were, that of 'climate tax collector' ${ }^{6}{ }^{6}$ and their only duty is to respect the privilege of the global poor inhabiting their territory to be exempted from that tax. It is in this sense that the transition from the first to the second GDR framework could be seen as a shift from national development claim rights to global rich obligations.

The Oxford framework, in a sense, picks up the idea implicitly encapsulated in the first version of the GDR framework - namely that poor people have a claim right for their lot to be advanced (for poverty to be alleviated) - and that they have this claim vis-à-vis their governments. Governments are still seen to have an obligation towards the international community - to shoulder a fair share of the climate burden - but their obligation towards their poor population takes precedence. \#

\begin{tabular}{|rccccccc|}
\hline \multicolumn{7}{|c|}{ Table III.3.i. GDR-2 ‘Country Statistics’ (I) } \\
\hline Country & pop. & poor & GDP & GDP/cap & DN & CapInc & $\boldsymbol{C I}^{\dagger}$ \\
\hline A & 100 & 54 & $\$ 986 \mathrm{k}$ & $\$ 10 \mathrm{k}$ & $\$ 243 \mathrm{k}$ & $\$ 329 \mathrm{k}$ & $82 \%$ \\
B & 50 & 34 & $\$ 346 \mathrm{k}$ & $\$ 7 \mathrm{k}$ & $\$ 175 \mathrm{k}$ & $\$ 71 \mathrm{k}$ & $18 \%$ \\
\hline \multicolumn{1}{c}{} & & \multicolumn{7}{c}{${ }^{\dagger}$ Relative to CapInc $_{A}+$ CapInc $_{B}$} \\
\hline
\end{tabular}

\section{OCM: National Poverty Obligation Needs}

To explain how the Oxford Capability Measure can be regarded as an extension of the original GDR framework, and to compare it directly with the GDR-2 framework, consider the variant of the OCM scenario in which:

(i) there is no progressive prosperity adjustment (in other words $\delta=0$ ), meaning that the figure for the Oxford Gross Capability measure (represented by the blue area in Figure III.3.i.a) is that of GDP, and

(ii) the poverty capability allowance is $\$ 9000$ per poor person, for all countries $\left(\Pi_{k} \equiv 9000\right)$.

Applying these assumptions in the context of our hypothetical examples (say Country A) allows us not only to depict the Oxford Gross Capability (Figure III.3.i.a) in analogy to the GDR representation used for the GDP of Country A in Figure III.2.ii.a, but also to associate the GDR 'development need' of that country ( $D N_{A}$, see Figure III.2.i.a) with poverty capability allowances (light green area in Figure III.3.i.b) which are surplus to what is needed to cover the income of the poor (dark green area in Figure III.3.i.b).

\footnotetext{
${ }^{68}$ To be sure, this is not to say that governments cannot be seen to have other obligations, but merely that, for the purposes of the GDR-2 approach, they only need to make sure that the relevant payments are made.
} 

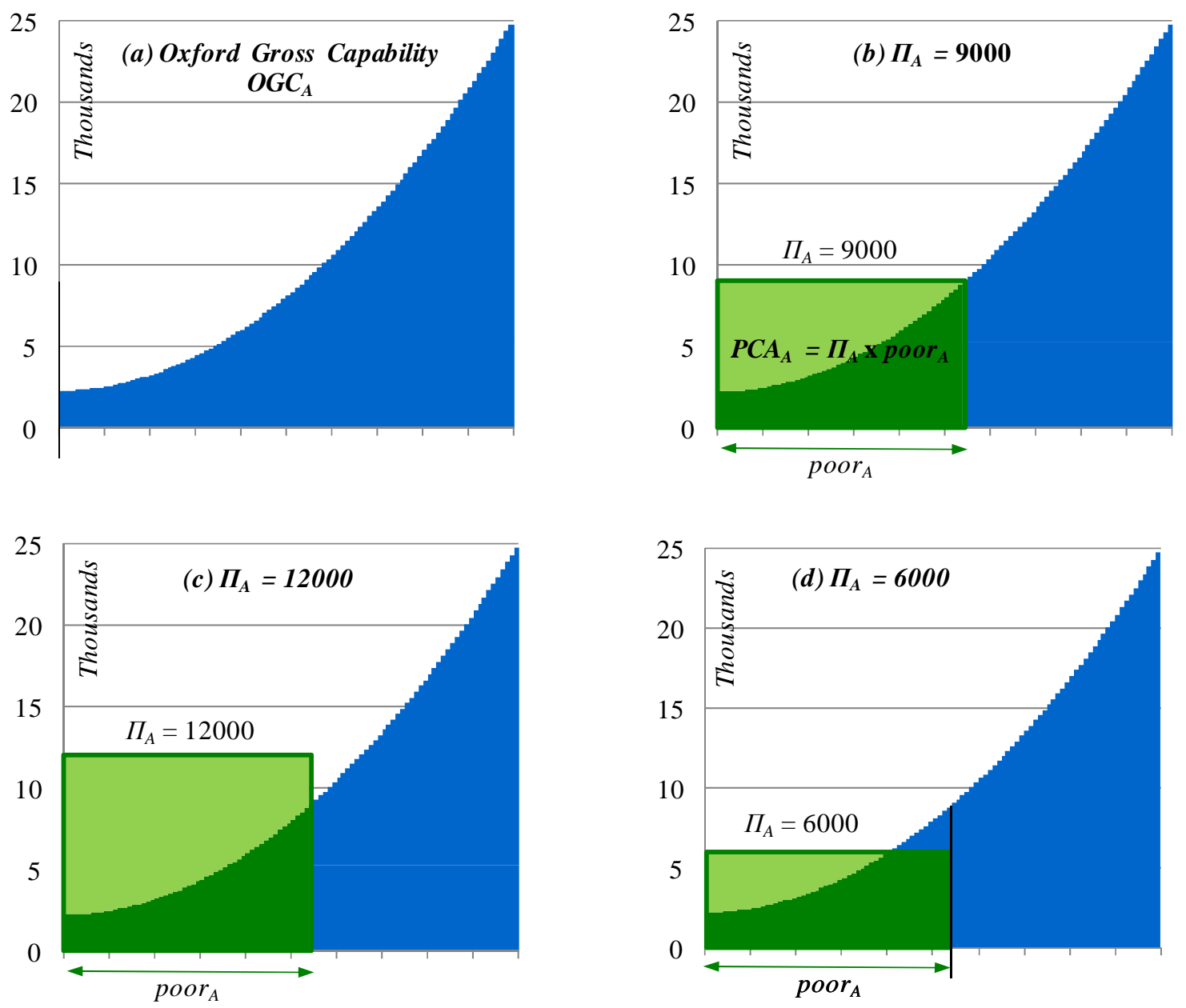

Figure III.3.i. The non-progressive OCM framework (I):

Oxford Gross Capability \& Poverty Capability Allowances $\Pi_{k} /$ Adjustments $P C A_{k}$

However, to avoid misunderstandings, three facts about the OCM framework need to be highlighted in this context. First, there is the fact that the OCM is not measured in monetary terms, but in dimensionless units (albeit calculated on the basis of monetary, namely GDP, figures), which is why the vertical axes in the diagrams of Figure III.3.i are unit-less. ${ }^{69}$ The second is that the OCM framework does not rely on defining poverty in terms of some income level. Indeed, personal incomes and income distributions are not relevant in that framework: what is needed is the sizes of the poor populations, however they may be defined. And finally, the (related) fact that poverty capability allowances (again unit-less numbers) are also not meant to reflect some normative income level 'where poverty ends' ${ }^{70}$ they are parameters used to calculate poverty capability adjustments: $P C A_{k}=$ poor $_{k} \times \Pi_{k}$, to be netted from the respective gross capabilities. ${ }^{71}$ An allocation to people - as

\footnotetext{
${ }^{69}$ As it happens, in the chosen 'no-prosperity-progression' scenario, the gross capability figures are the same as the relevant GDP numbers, but they are mere numbers, nonetheless.

${ }^{70}$ Note, in this context, that 'being poor' is not necessarily tied to this sort of income level.

${ }^{71}$ To be fair, the choice of the poverty capability allowances, like the choice of the GDR poverty threshold, has a normative element. The difference is that the latter is about what should be a 'dignified level of human development free from the privations of poverty' whereas the former is about a group of countries that should
} 
practised in the GDR framework - could hence lead to a surplus even for the highest-earning poor person (Figure III.3.i.c), or there could be poor people whose income is not completely covered by the allowance (Figure III.3.i.d).

\begin{tabular}{|c|c|c|}
\hline \multicolumn{3}{|c|}{$\begin{array}{l}\text { Table III.3.i. } \\
\text { OCM ‘Country Statistics' (I) }\end{array}$} \\
\hline \multirow{3}{*}{\multicolumn{2}{|c|}{$\begin{array}{l}G D P_{A} \\
O G C_{A} \\
G D R \text { development } \\
\text { need } D N_{A} \\
\end{array}$}} & \multirow{3}{*}{$\begin{array}{l}\$ 986 \mathrm{k} \\
986 \mathrm{k} \\
\$ 243 \mathrm{k}\end{array}$} \\
\hline & & \\
\hline & & \\
\hline$\Pi_{A}$ & $P C A_{A}$ & $\begin{array}{c}\text { OCM Surplus } \\
\text { Allowances }\end{array}$ \\
\hline 12000 & 648000 & 405101 \\
\hline 9000 & 486000 & 243101 \\
\hline 6000 & 324000 & 81101 \\
\hline
\end{tabular}

Yet one, if not the, key difference between the Oxford and the GDR-2 framework is precisely that these allowances are not allocated to people but to a country as a whole. Moreover, the aim of providing these allowances is not to obtain money from any particular sector of society, rich or poor, but to enable countries to fulfil their (national) obligations towards their poor by giving them 'economic breathing space' to do so, prior to fulfilling their (international) climate change obligations.

The Oxford measure OCM - corresponding in function to the GDR 'Capable Income' (CapInc ${ }_{k}$, see Figure III.2.i) - is given by subtracting the Poverty Capability Adjustments $\left(P C A_{A}\right.$, Figure III.3.i.b) from gross capabilities (Figure III.3.i.a). Graphically, this means subtracting the surplus allowances that remain after the income of the poor has been covered (light green areas, Figure III.3.ii) from what could be termed the 'gross capability of the rich' (blue areas). The three diagrams in the right hand column of Figure III.3.ii depict the result of this subtraction.

The first thing to be noted is that - given the chosen correspondence of the allowance level to the GDR development threshold - this operation can be interpreted as taking seriously the idea of the (GDR) 'development need' as the right of the country to an exemption with regards to financial climate change obligations because of overriding obligations towards their poor. As illustrated in Figure III.3.ii (a) and (b), the Oxford measure $\left(O C M_{k}\right)$ can be larger or smaller than the corresponding GDR Capable Income (Figure III.2.i). Where the analogy breaks down is in the fact that under the Oxford method, it is possible for development needs to be so great that the capability measure becomes negative, reflecting, as it were, a country's 'poverty obligation headroom' (Figure III.3.ii.c).

To sum up. While it is possible, under certain constraining assumptions, to interpret the Oxford Capability Measure and Index as an extension of the original GDR-1 approach, there are fundamental philosophical differences between the Oxford methodology and, in particular, the revised GDR-2 approach.

The Oxford methodology has the country as the fundamental unit of analysis, with reference only to one 'domestic' issue, namely the size of the poverty problem. The GDR-2 methodology, in contrast, focuses on individuals (and their incomes) as 'global citizens' in other words, disregarding any characteristics of the country inhabited. Indeed, as concerns the GDR-2 measure, the focus is on the 'global rich', defined as individuals with a personal income above some 'development threshold'. We believe that this fails to take into account the 'development needs' of countries, which arise out of their obligations to their poor populations, an issue that is at the heart of the Oxford methodology.

(on the whole) not be forced to contribute to climate change costs (namely the Group of Least Developed Countries). 

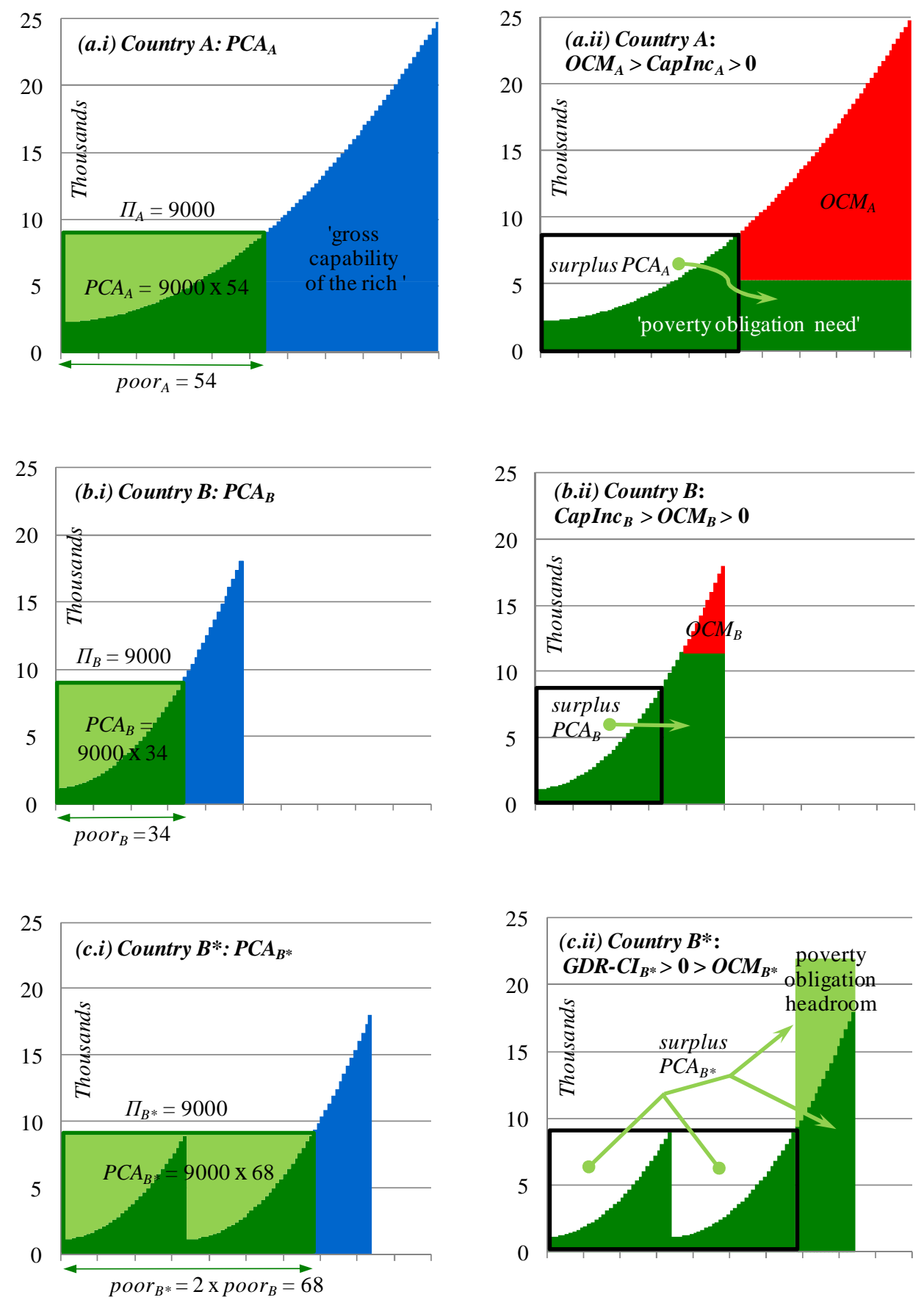

Figure III.3.ii. The non-progressive OCM framework (II)

Table III.1 OCM 'Country Statistics' (II)

\begin{tabular}{|c|c|c|c|c|c|c|c|c|}
\hline Country & pop. & poor & $G D P$ & GDP/cap & $P C A$ & $O C M$ & OCI & $C I$ \\
\hline $\boldsymbol{A}$ & 100 & 54 & $\$ 986 \mathrm{k}$ & $\$ 10 \mathrm{k}$ & 486 & 500 & {$[1]$} & [2] \\
\hline $\boldsymbol{B}$ & 50 & 34 & $\$ 346 \mathrm{k}$ & $\$ 7 \mathrm{k}$ & 306 & 38 & $7 \%^{\dagger}$ & $18 \%^{\dagger}$ \\
\hline$B^{*}$ & 84 & 68 & $\$ 477$ & $\$ 6$ & 612 & -135 & $0 \%{ }^{\#}$ & $18 \%$ \\
\hline
\end{tabular}




\section{The Oxford Measure: Discussion and illustrative examples}

In Part II, we explained how, by design, the proposed gross capability measure has a degree of progressivity/vertical equity akin to national tax systems. We also looked at the sensitivity of these capabilities with regard to the choice of the progressivity parameter $(\delta)$, and we do the same in Appendix 3 for the general poverty capability allowance $(\Pi)$ which, when deducted (as poverty capability adjustment) from the gross capabilities, gives the (net) Oxford Measure. In Part III, we illustrated the manner in which this net measure takes into account the size of national poverty by comparing it with the well-known Greenhouse Development Rights approaches. The time has now come to give some concrete illustrative examples of this net capability measure. We will start by looking at the Oxford Capability Measures of a number of countries, based on 2009 data, seeing how they can be used in allocating 'fair' costs/burdens, and then proceed to illustrate how a net negative capability can be interpreted in terms of an amount of growth catch up, or poverty reduction, that has to take place before that country's capability index becomes positive. Finally, we turn our attention to the issue of using these economic capability measures to introduce country categories, such as 'high capability' or 'low capability' countries in the context of graduation schemes, that is, of differentiated country obligations.

\section{AsSESSing the Distribution OF Climate IMPACT Costs}

\subsection{Capability Estimates}

In Section I.2, we noted that the intended purpose of introducing capability measures was to contribute to methodologies aimed at ascertaining whether distributions of costs/burdens associated with the global climate change effort are just/fair or not. For this purpose, we have introduced an Oxford Gross Capability measure $O G C_{k}$ and a (net) Oxford Capability Measure $O C M_{k}$, and associated indices $O G C I_{k}$ and $O C I_{k}$, with the latter taken to define the normative benchmark as to what would constitute a fair distribution of costs/burdens among a group of countries $\Gamma$, if one were to base these considerations purely on respective economic capabilities (always keeping in mind the relevant caveats mentioned in Section I.2). In other words, the idea is that a cost/burden distribution is to be considered fair if (and only if) it corresponds to the chosen Capability Index (that is, if and only if, $k$ 's share of the total cost/burden $\Omega$ is the same as its capability index: $\Omega_{k}=C I_{k}$ ).

To illustrate this, let us begin with some remarks about the general nature of the Oxford Capability Measure. We would first like to highlight the fact that the characteristics elaborated for the Base and Gross Capabilities with reference to scale and aggregation invariance (Section II.1.4) are carried over to the (net) Oxford Capability Measure $\left(O C M_{k}\right)$ and Index $\left(O C I_{k}\right)$ because the relevant General Poverty Capability Allowances $(\Pi)$ are assumed to have the same units as the relevant GDP figures. ${ }^{72}$ In other words, the net measure transforms under scale changes as needed, for example: $O C M_{k}[\$]=$ $O C M_{k}[\Phi] / 100 .^{73}$ Indeed, it is true in the following that the Oxford Capability Index is scale invariant - in particular that:

$$
O C I_{k, \Gamma}[\$]=O C I_{k, \Gamma}[\Phi] \quad(\text { for all groups of countries } k \in \Gamma)
$$

\footnotetext{
72 Note, however, that since the Oxford Gross Capability is a dimensionless score, Poverty Capability Adjustments are also dimensionless, and the transformation $\Pi[\Phi]=100 \times \Pi[\$]$ (referring in square brackets to the monetary units used for the Base Capability) is assumed in order to achieve the desired scale invariance of the Oxford Measure.

${ }^{73} O C M_{k}[\$]=\left(\gamma_{k}\right)^{\delta} \times G D P_{k}[\$]-\Pi[\$] \times P_{k} \times M P I_{k}=\left(\gamma_{k}\right)^{\delta} \times 100^{-1} \times G D P_{k}[\Phi]-100^{-1} \times \Pi[\Phi] \times P_{k} \times$ $M P I_{k}=100^{-1} \times\left[\left(\gamma_{k}\right)^{\delta} \times G D P_{k}[\Phi]-\Pi[\Phi] \times P_{k} \times M P I_{k}\right]=100^{-1} \times O C M_{k}[\$]$
} 
- and also that its proportions are aggregation invariant and the same as the proportions of the relevant capability measures themselves, in the sense that:

$$
O C I_{n, \Gamma_{1}}: O C I_{m, \Gamma_{1}}=O C I_{n, \Gamma_{2}}: O C I_{m, \Gamma_{2}}=O C M_{n}: O C M_{m} \text { (for all } \Gamma_{1}, \Gamma_{2} \text { with } n, m \in \Gamma_{1} \cap \Gamma_{2} \text { ) }
$$

Accordingly, we shall again avoid using numbers to label the diagrams of capability levels and rely only on gridlines to help in representing their proportions.

Figure IV.1.i depicts the 2009 (net) capabilities of a number of economies, arranged in order of their prosperity levels (per capita GDP), and their overall economic size (GDP). The relative proportions of capabilities can easily be read from the figures. What also emerges nicely is that neither prosperity level nor economic size can be used as a proxy for (net-) capability to pay, certainly at the less

Figure IV.1.i. Oxford Measure - Sample of Capabilities, $\delta=0.5, \Pi=2 \times Z C A_{L D C}$
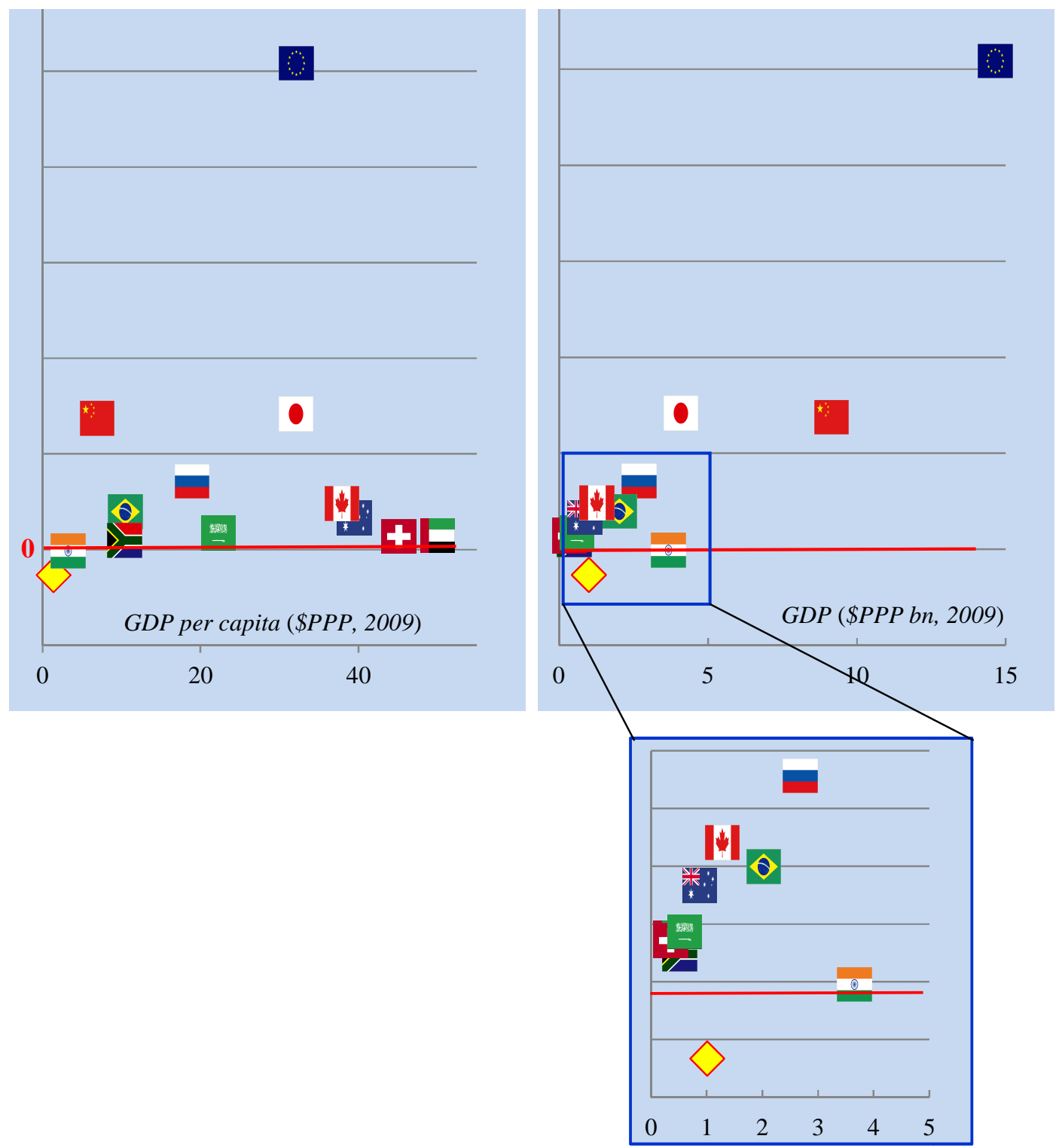
prosperous end of the spectrum. ${ }^{74}$

In other words, economic capability - in the sense of ability to share the cost of climate change action, as conceived in the Oxford approach - is co-determined by a number of factors (overall economic size and prosperity, as well as the size of poverty). None of these factors on their own can be taken as a proxy. In particular - as witnessed by the case of India - one cannot necessarily infer from the fact that a country is 'large' that it has high capability (to pay). Nor does having low capability imply low prosperity (as witnessed by Switzerland or Qatar), in the same way in which paying little tax does not necessarily imply one is poor.

What one can, and is (as mentioned earlier), meant to do with these economic capability figures is to use them in the form of normalized indices to provide a benchmark for fair/just cost/burden-sharing.

\subsection{Climate Impact Costs: Climate Vulnerability Monitor 2012}

There are many types of relevant costs/burdens that countries are facing in the context of climate change, ranging from climate finance contributions to costs imposed by climate impacts. Given the recent publication by DARA $^{75}$ of figures relating to the latter in the second edition of the Climate Vulnerability Monitor (CVM2), ${ }^{76}$ we thought it might be interesting to have a look at their distribution among countries, and how it compares to the Oxford (Gross) Capability Index benchmark:

'A "Climate", meaning Climate Change, impact/vulnerability assessment including 22 indicators across four Impact Areas (Environmental Disasters, ${ }^{[77]}$ Habitat Change, ${ }^{[78]}$ Health Impact, Industry Stress ${ }^{[79]}$ ) measuring the positive and negative effects of climate change as they are experienced by 184 countries worldwide in socio-economic terms, in particular for the timeframes of 2010 and 2030. ${ }^{80}$

'The Monitor's data outputs are given both as levels of vulnerability and as estimates of the levels of absolute (i.e. dollar ${ }^{[8]]}$ gain) and/or relative (i.e. percentage loss of GDP) loss or gain - termed “impact" - implied by today's (2010) or tomorrow's (2030) situation, which is a scenario with climate change (N.B. information has also been compiled for the year 2000, however this data does not figure in the final report). With respect to vulnerability, the level of impact is deemed indicative of the level of vulnerability. Meaning, where impacts are more significant in relative terms (i.e. in relation to the size of the economy or population), vulnerability is taken to be higher. The approach has been termed "outcome vulnerability", since it is the outcome of the vulnerability - the degreelabsence of harm incurred - that is the indicator of the level of vulnerability present in the first place. ${ }^{, 82}$

\footnotetext{
${ }^{74}$ It follows from the definition of our gross capability that: $O G C_{k}^{\delta} / G D P_{k}=\alpha \times\left(\gamma_{k}\right)^{\delta}$ with $\alpha=\left(g d p_{\text {world }}\right)^{-\delta}$, which means that for countries without poverty adjustments, one can expect a reasonable correlation between capability and GDP for countries with similar prosperity

${ }^{75}$ The independent organization committed to improving the quality and effectiveness of aid for vulnerable populations which, among other activities, monitors the human impact of climate change.

${ }^{76}$ CVM2. 'Climate Vulnerability Monitor (2nd. Edition): A guide to the cold calculus of a hot planet', http://daraint.org/climate-vulnerability-monitor/climate-vulnerability-monitor-2012/report/

${ }_{77}^{77}$ Drought, floods \& landslides, storms, wildfires.

${ }^{78}$ Biodiversity, desertification, heating \& cooling, labour productivity, permafrost, sea-level rise, water.

${ }^{79}$ Agriculture, fisheries, forestry, hydro energy, tourism, transport

80 'Methodological Documentation for the Climate Vulnerability Monitor, 2nd Edition', September 2012, 4. www.daraint.org/cvm2/method.

${ }^{81}$ Measured in purchasing power parity (PPP) terms.

82 'Methodological Documentation for the Climate Vulnerability Monitor, 2nd Edition', September 2012, 5. www.daraint.org/cvm2/method.
} 


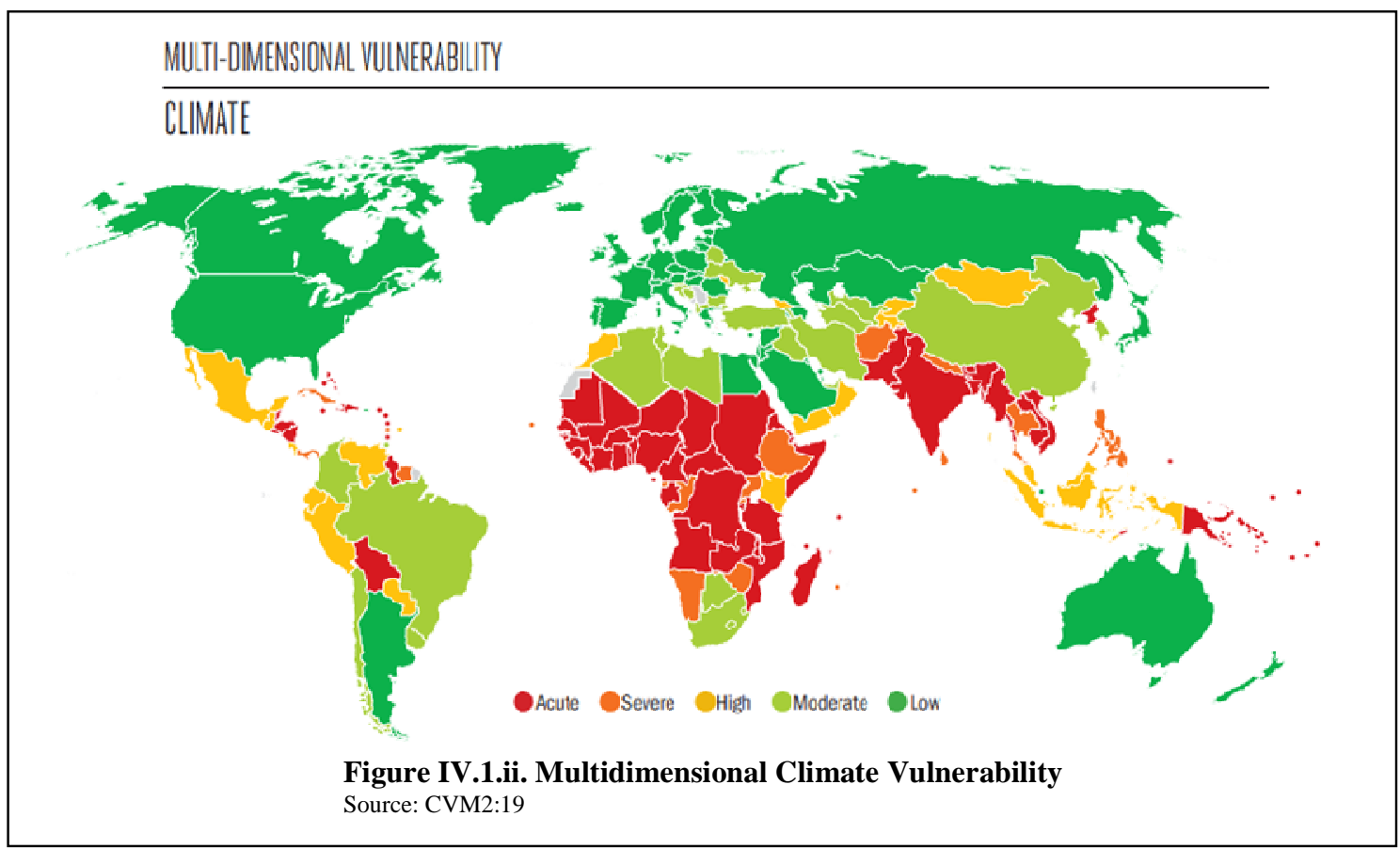

Figure IV.1.ii depicts the regional distribution of these relative impacts, which reflect the 'impact cost intensity of GDP', in other words, the percentage changes in GDP due to climate impacts.

What is very disconcerting is the fact that this distribution is very similar to the regional distribution of what might analogously be termed '(multidimensional) poverty vulnerability' as depicted in Figure IV.3.iii (Poverty intensity of GDP: Geographical distribution). While it would be interesting (but beyond the scope of this paper) to find out the extent to which poverty intensity and impact cost intensity are independent, the simple fact that the correlation exists means that the more economies are stressed with poverty, the more they are also stressed by climate impacts. This, by itself, should justify incorporating the size of the poverty problem into economic capabilities, as we have done in our move from gross to net capability measures.

Figure IV.1.iii represents these cost impact intensities in a more disaggregated fashion. It not only displays the extreme ranges estimated by DARA - from GDP losses of over 30 per cent (Marshall Islands) to gains (in other words 'negative costs') of just under 1 per cent (Finland) - but it also shows the different exposures of some of the main country groupings, both within themselves and in comparison to some large economies. It also provides a representation that is both literally and figuratively 'graphic' of the reason why the majority of African, least developed and small island countries are generally referred to as among the 'particularly vulnerable' ones. 


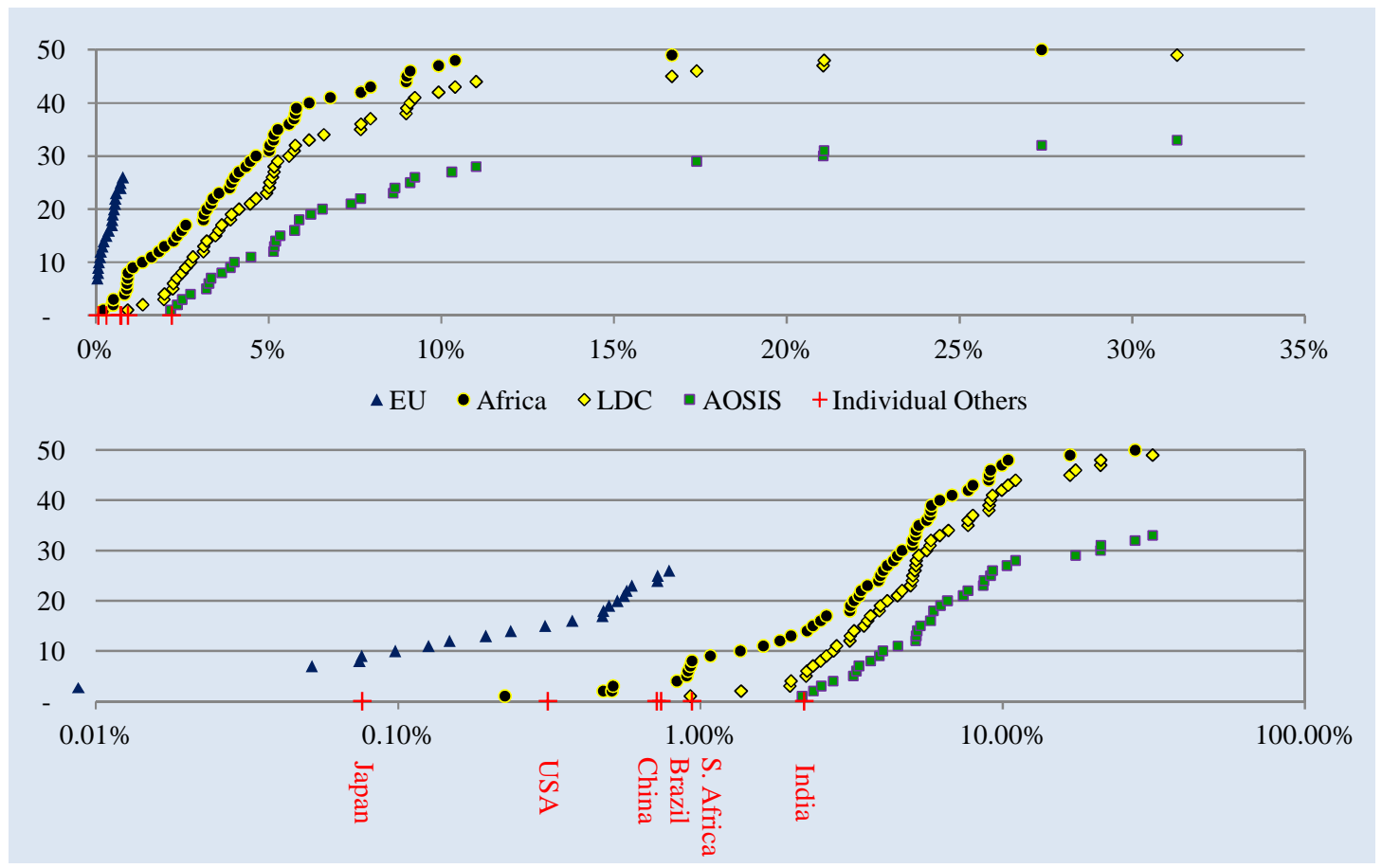

Figure IV.1.iii. 2010 Impact Cost Vulnerability Levels (percentage of GDP)

\subsection{Cost Distribution, Capability Distributions, Excess Costs, and Degrees of Inequity}

Turning now to assess the distribution of absolute impact costs against our capability-based benchmark(s), we focus on the 2010 data set, not least because it corresponds with the data we use to estimate our capability figures. However, two modifications proved to be necessary for this. For one, we had to exclude some of the countries reflected in the DARA data set due to a lack of Multidimensional Poverty Index (MPI) data required to calculate our poverty capability adjustments (see Section II.2). For reasons explained in Box IV.1.i, we also transformed the DARA data into a 'pure' cost data set, assigning zero cost to all countries that were estimated to have an impact benefit.

\section{Box IV.1.i. Cost and Benefit v. Cost/Benefit Distributions}

Apart from 'proper' impact costs, the DARA database also includes benefits, and it does so by representing them as negative costs. While this may be useful in a number of contexts, it is not appropriate to mix benefits and costs in this 'cost/benefit' manner for our purposes.

For one, by allowing benefits to be netted from costs, the notion of a percentage of the cost/benefit sum total ceases to be extensive, in the sense that the percentages of all the 'shares' no longer add up to the whole $(100 \%)$. Indeed if the overall sum total of cost and benefits (negative costs) happens to be zero, then the percentage is not even well-defined anymore.

Another reason is the fact that our capability measure, by design progressive, may not really be appropriate in distributing benefits: why should those who are better off receive more per unit of GDP than those who are worse off? And this inappropriateness remains even if the benefits are mixed in with costs.

For this reason, it is important to separate the issue of cost distributions from that of benefit distributions. Fortunately, a cost/benefit data set such as the DARA impact costs can easily be separated into a pure cost and a pure benefit component, simply by setting appropriate zero levels (for negative costs, and negative benefits respectively). 
Our illustrative example is thus based on a data set of 143 countries with a total impact cost of $\$ 560 \mathrm{bn}$ (2010 PPP).

According to CVM2, 18 per cent of the estimated 2010 impact costs are borne by 'developed' (12 per cent) and 'other industrialized' countries; the rest by developing countries, split into 'high emitters' (46 per cent) and low emitters' (36 per cent). ${ }^{83}$ In the slightly reduced data set considered here, over two-thirds of the costs are concentrated in 10 countries, and more than half in the five countries listed in Table IV.1.i: India, China, Mexico, USA, and Indonesia.

\begin{tabular}{|l|l|l|l|l|l|l|l|l|}
\hline & \multicolumn{2}{|l|}{ GDP/cap } & \multicolumn{2}{l|}{ Costs (2010) } & \multicolumn{3}{l|}{ Capabilities (2009) } \\
\cline { 2 - 10 } & $\begin{array}{l}2009 \\
\text { \$PP }\end{array}$ & $\begin{array}{l}\text { Costs } \\
(\$ b n)\end{array}$ & $\%$ & $\begin{array}{l}\% \text { of } \\
\text { GDP }\end{array}$ & OCI & $\begin{array}{l}\text { OCI } \\
\text { Excess }\end{array}$ & OGCI & $\begin{array}{l}\text { OGCI } \\
\text { Excess }\end{array}$ \\
\hline India & 3167 & 89 & 16 & 2.2 & $0 \%$ & 89 & $2 \%$ & 78 \\
\hline China & 6863 & 72 & 13 & 0.7 & $7 \%$ & 31 & $8 \%$ & 30 \\
\hline Mexico & 13859 & 48 & 9 & 3.1 & $2 \%$ & 38 & $2 \%$ & 38 \\
\hline USA & 45793 & 45 & 8 & 0.3 & $31 \%$ & -129 & $30 \%$ & -122 \\
\hline Indonesia & 4085 & 36 & 6 & 3.5 & $0.5 \%$ & 34 & $0.6 \%$ & 33 \\
\hline EU & 32099 & 26 & 5 & 0.2 & $28 \%$ & -128 & $27 \%$ & -122 \\
\hline LDCs & 1373 & 25 & 4 & 2.5 & $0 \%$ & 25 & $0.3 \%$ & 23 \\
\hline
\end{tabular}

Table IV.1.i. Cost Shares, Capability Shares, and Excess Cost Figures

Figure IV.1.iv. displays, in (a), the respective total cost shares of these (in absolute terms) top five impact cost sufferers/sharers, together with the share of the EU and the LDC Group aggregates. It also represents the benchmark shares given (b) by the Oxford (net) Capability Index (OCI), and (c) by the Oxford Gross Capability Index (OGCI).

Two things become clear from this visual representation: First, in the cases illustrated there is actually not much difference between the net capability benchmark, which takes into account the size of the poverty problem, and the gross capability benchmark, which does not. Second, the actual cost distribution is significantly different from either of these benchmarks. So what?

As concerns the difference between the estimated impact cost distribution and the distribution corresponding to our operationalization of respective economic capabilities, one might think that this is just a matter of 'bad luck', were it not for the fact that these costs are man-made, which turns the issue into one of distributive justice. Assuming, with the caveats issued at the very beginning of this paper, that one were to judge the fairness of this distribution only in terms of respective (economic) capabilities, the difference would suggest a significant degree of unfairness.

Indeed, given a benchmark - such as the one given by the OCI shares $O C I_{k}$ - we can define the concept of 'Excess Cost Shares' $E C S_{k}$ as the difference between the 'actual' cost shares $A C S_{k}$ and the relevant benchmark cost shares $B C S_{k}$ :

$$
E C S_{k}={ }_{\text {def }} A C S_{k}-B C S_{k} .
$$

${ }^{83}$ (CVM2, 16). 


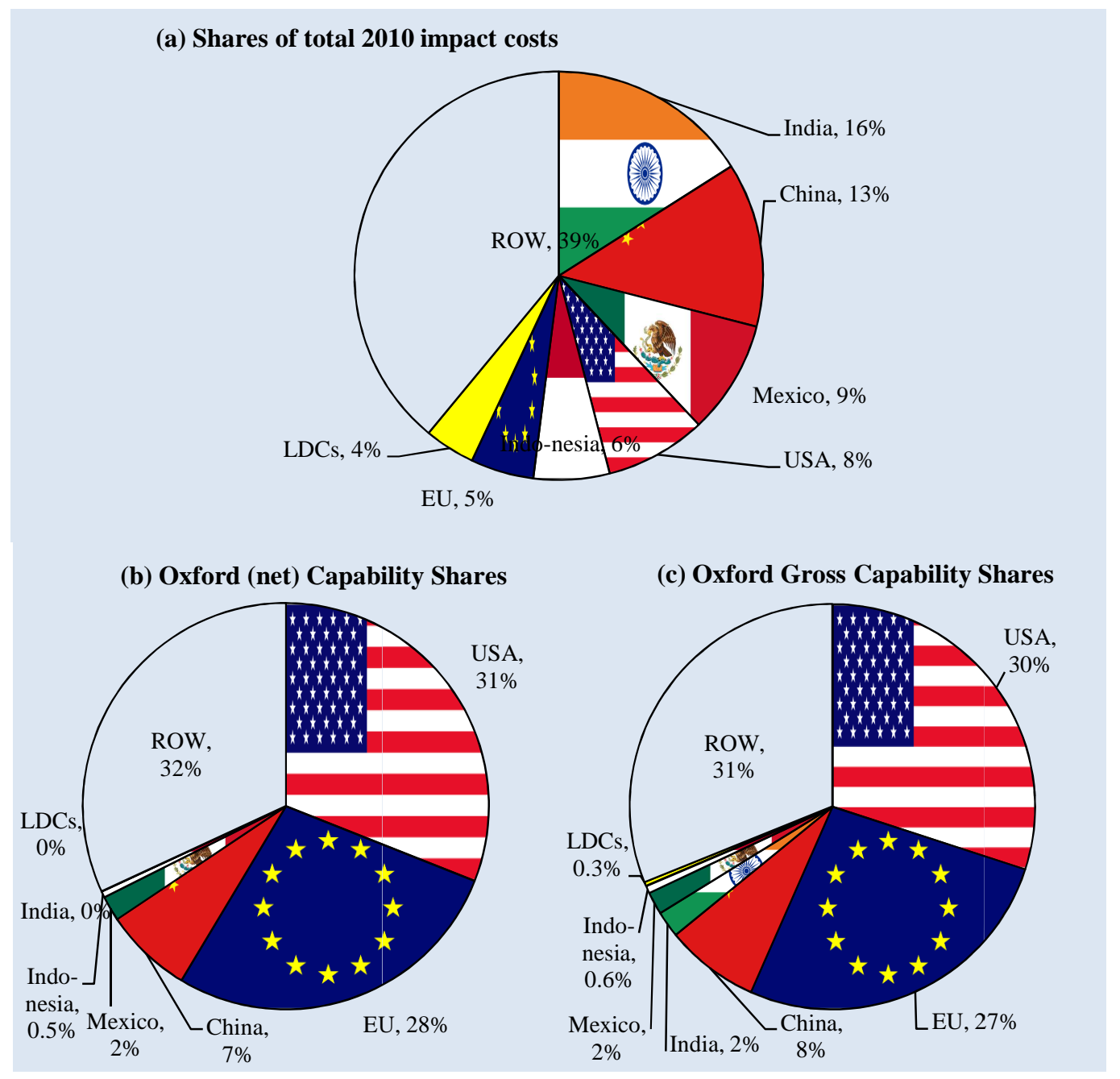

Figure IV.1.iv. Impact Cost and Capability Distributions

Unless the actual distribution is identical with the benchmark - that is, $A C S_{k}=B C S_{k}$ (for all $k$ ) there will be both positive and negative excess cost shares, reflecting actual cost shares that are larger or smaller than the respective benchmark shares. Indeed, the magnitude of the sum of these positive ${ }^{84}$ excess cost shares:

$$
E C S^{+}=_{\text {def }} \sum_{k} E C S_{k}^{+} \text {with } E C S_{k}^{+}={ }_{\text {def }} \max \left(E C S_{k}, 0\right)
$$

can be used as a measure of the total deviation between the two distributions; in other words - given that the benchmark is meant to define the equitable distribution - a measure of the level of inequity of the actual distribution, relative to that benchmark. $E C S^{+}$is an index in that it ranges from 0 to 1 , with the former indicating that the actual distribution is identical with the benchmark, and the latter that one party covers all the actual costs which, according to the benchmark, should not cover any:

\footnotetext{
${ }^{84}$ Choosing the positive excess cost shares here is, of course, just a matter of convention. One could equally well have chosen the sum of the negative ones:

$E C S^{-}=_{\text {def }} \sum_{k} E C S_{k}^{-}$with $E C S_{k}^{-}={ }_{\text {def }} \min \left(E C S_{k}, 0\right)$, since $E C S^{+}=-E C S^{-}$.
} 


$$
\begin{aligned}
& 0 \% \leq E C S^{+} \leq 100 \%{ }^{85} \\
& E C S^{+}=0 \% \text { iff } A C S_{k}=B C S_{k} \text { (for all } k \text { ): completely fair. }{ }^{86} \\
& E C S^{+}=100 \% \text { iff } A C S_{k}=100 \%, B C S_{k}=0 \% \text { (for some } k \text { ): completely unfair. }{ }^{87}
\end{aligned}
$$

Applying this measure to a distribution of the DARA impact costs compared to the OCI (OGCI) benchmark, we find a level of inequity of 63 per cent ( 60 per cent).

Given that what is being assessed are monetary costs, there is in principle a simple way to rectify this situation, namely through Excess Cost Transfers:

$$
E C T_{k}={ }_{\text {def }} E C S_{k} \times \Omega(\text { with } \Omega=\text { the total cost involved })
$$

where countries receive $\left(E C T_{k}>0\right)$ or pay $\left(E C T_{k}<0\right)$ money in order to reduce the inequity level to zero. Table IV.1.i. lists some of the resulting transfers that would have to be carried out in order to render the DARA impact cost distribution equitable relative to the OCI and OGCI benchmarks. The practical problem with this solution is, of course, its magnitude: the sum total of transfers that would be required to rectify the inequity would be $E C S^{+} \times \$ 560 \mathrm{bn}$, that is, $\$ 352 \mathrm{bn}$ ( $\$ 335 \mathrm{bn}$ ) relative to the OCI (OGCI) benchmark.

It has to be stressed that these figures have to be treated with some caution. Apart from the fact that there may be methodological issues in relation to the calculation of the impact cost figures, it is likely that the figures reported do not include all impacts, and obviously they do not include other climate related costs such as those incurred in mitigation. On the benchmark side, we also have to reiterate that the benchmarks developed here only involve respective economic capabilities, and thus do not reflect other aspects, in particular differentiated responsibilities.

Yet given the orders of magnitude (both absolute and relative) of the figures, we believe that the overall pattern emerging here would not change fundamentally and that some general lessons can be drawn despite all these caveats. Above all, the lesson has to be that there is likely to be a significant level of inequity in the overall distribution of climate-related costs across the globe, regardless of which particular equity benchmark is chosen, and that it is highly unlikely that the level of climate finance available will suffice to remedy this through excess cost transfers.

This means, in particular, that the design of any international climate finance scheme should take into account these overarching issues, in order not to aggravate them. Take, for example, the Green Climate Fund which is currently being operationalized. The point is: the design of the resource allocation and contribution frameworks should not be seen in isolation but reflect these general cost distribution issues through, say, eligibility prioritizations and contribution dispensations. In theory, the best way of doing so would be to restrict eligibility to countries with overall positive excess costs, and contribution to countries with overall negative excess costs. In practice, it is difficult to see whether there could be an agreement on the assumptions required to calculate such overall excess costs. Instead, one might prioritize eligibility in terms of (impact) cost intensities of GDP, such as those illustrated in Figure IV.1.iii (2010 Impact Cost Vulnerability Levels), and introduce exemptions from

85 (i) If $A C S_{k}=O C I_{k}$ then $E C S_{k}=0 \%$ (for all $k$ ), hence $E C S^{+}=0 \%$.

(ii) If $A C S_{k}=100 \%$ then $A C S_{n}=0 \%$ (for all $n \neq k$ ), and hence $E C S^{+}=A C S_{k}-O C I_{k}$. Thus if $O C I_{k}=0 \%$ then $E C S^{+}=100 \%$.

${ }^{86} E_{C S}^{+}=0 \%$ iff $E C S_{k}^{-}=0 \%$, hence $E C S_{k}^{+}=0 \%$ and $E C S_{k}^{-}=0 \%$ (for all $k$ ), hence $A_{C S}=O C I_{k}$ (for all $k$ ).

${ }^{87} E_{C S}{ }^{+}=100 \%$ iff $E C S^{-}=-100 \%$ 
contributing in terms of poverty intensities of GDP (see Section IV.3) ${ }^{88}$ While neither of these proxies can be guaranteed not to aggravate the overall cost distribution issue - not least because of its inherent lack of acceptable specification - it stands to reason that they are highly likely not to do so (excessively).

\section{HEADROOM FOR COUNTRIES WITH NEGATIVE CAPABILITY}

How can we interpret and compare the situation of those countries with negative (net) capability? As concerns sharing climate change costs/burdens, they are all treated on a par by the Oxford Capability Index: they are all exempt from having to shoulder any burden (see Section II.2.3). Yet there is some further information in the size of the net negative capability that can be usefully interpreted in terms of a 'headroom' for having to pay. This position is analogous to the situation of people who earn less than the basic income tax allowance. Not only do they not have to pay income tax, but the size of the allowance surplus will give them an estimate or forecast of the length of time for which they will not have to pay income tax, under certain personal income growth assumptions.

Our net measure for 'country capability to pay' (for climate change) similarly allows countries with negative capabilities to calculate different capability headrooms for different growth assumptions. For example, one can calculate how much the income of the average inhabitant (the per capita GDP) would have to increase at the same rate as the world average in order to reach positive capability (with poverty constant). We call this the growth headroom (denoted by $H D_{k}^{g}$ ).

To calculate this growth headroom, we make use of a counterfactual exercise where the general poverty capability allowance $\Pi$ is set at a level so as to render each country's capability zero, and solve for that level for each country. Thus, given the definition of the Oxford Measure (equation 2.30), for each country $k$, there is a 'Zero Capability Allowance' $\Pi_{k}^{0}$ at which the base GDP measure is covered by the allowances, and the capability is zero:

$$
\begin{aligned}
\Pi_{\mathrm{k}}^{0} & :=\left.\Pi\right|_{\text {OCM }_{k}=0} \\
& =\left.\Pi\right|_{O G C_{k}-P C A_{k}=0} \\
& =\left.\Pi\right|_{\left[\left(\gamma_{k}\right)^{\delta} \times G D P_{k}\right]-\left[\Pi_{k}^{0} \times P_{k} \times M P I_{k}\right]=0} \\
& =\left(\gamma_{k}\right)^{\delta} \times\left[G D P_{k} /\left(P_{k} \times M P I_{k}\right)\right]
\end{aligned}
$$

with $\gamma_{k}=\left(G D P_{k} / P_{k}\right):\left(G D P_{\text {world }} / P_{\text {world }}\right)$.

It then follows that the growth headroom for any country with negative capability is simply the proportion by which the Zero Capability Allowance lies below the general poverty capability allowance $(\Pi)$ that is actually used in the calculation of the net capability:

$$
H D_{k}^{g}=\Pi_{k}^{0} / \Pi[\%]
$$

One might also consider headroom solely in terms of poverty alleviation (holding GDP per capita fixed throughout). As it happens, in percentage terms, the reduction in the poverty problem required to reach positive capability is the same as the growth headroom. And so if a country achieves any weighted combination of growth and poverty headroom, such as 50 per cent of each, then it will have attained positive capability. It is also worth noting that if a country grows faster than the world average, meaning that it gets closer to world living standards, then its headroom will be reduced more

${ }^{88}$ The idea here is that while the level of contributions is assigned, say, in proportion to respective economic capabilities (and/or differentiated responsibilities), countries are exempted from contributing if their poverty intensity is higher than $n$ poor people per million of GDP. 
quickly than implied by equation (4.8). If it grows more slowly, then its headroom will take longer to eliminate. Therefore the growth headroom measure can be thought of as a benchmark comparative measure of headroom and not a forecast of what will happen.

With those caveats in mind, we can consider Figure IV.2.i, which shows the growth headroom for all countries with MPI poor and negative capability (Yellow diamonds $=$ LDC).

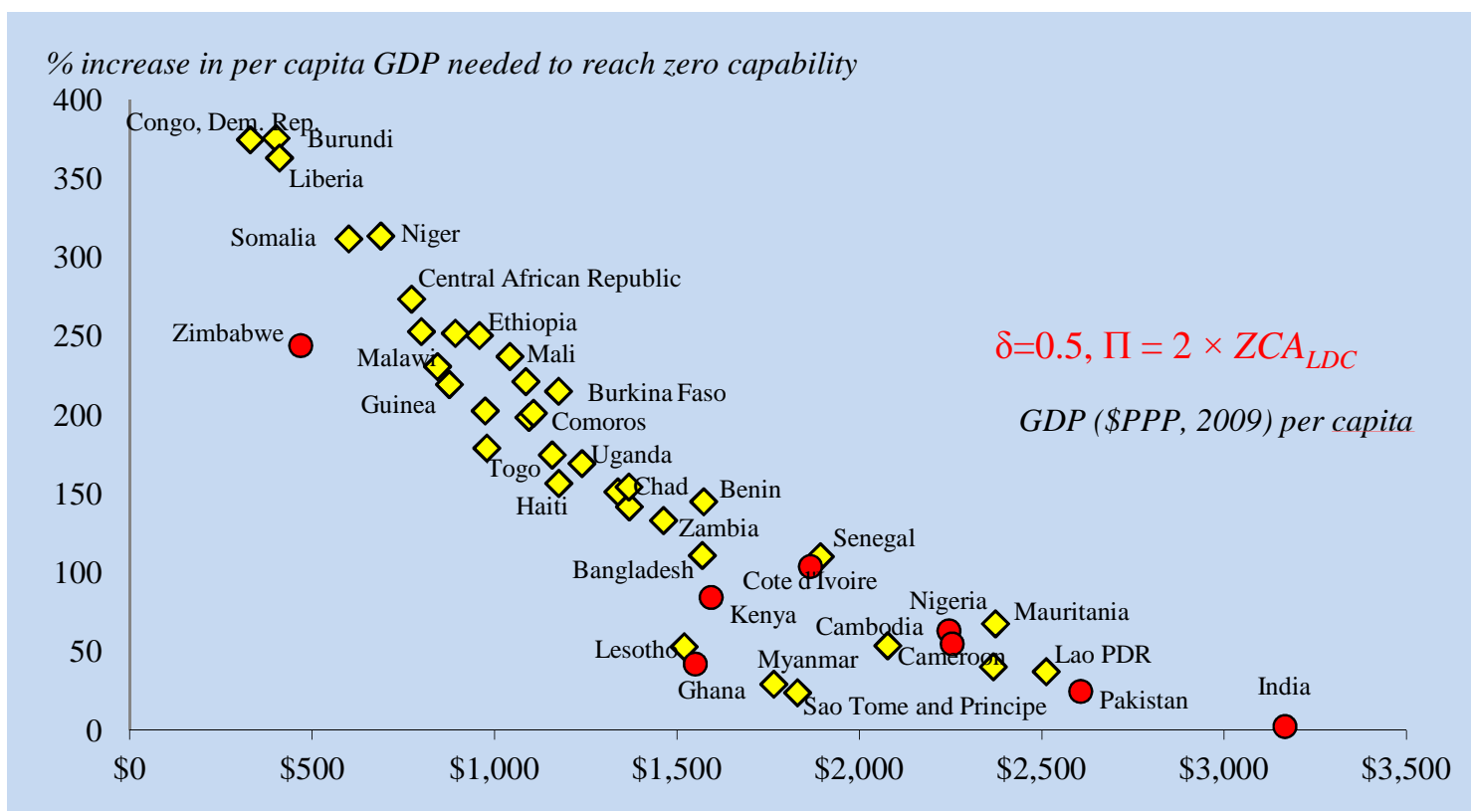

Figure IV.2.i: Growth Headroom (for countries with negative net capability)

It is important to keep in mind that the value of the general poverty capability allowance $(\Pi)$ underlying these figures was deliberately set to ensure that most LDCs have negative capability, or equivalently, growth headroom (see Appendix 3). Given this benchmark Figure IV.2.i. shows that India is on the cusp of having positive capability. For the poorer LDCs such as the Democratic Republic of Congo, the headroom is so large that it is unlikely to be closed in the near future: the DRC needs to quadruple its per capita income (with poverty constant and growth in line with world GDP per capita growth) before it has positive capability.

\section{CAPABILITY CATEGORIES?}

In 'To Tax or not to Tax: Alternative Approaches to Slowing Global Warming, ${ }^{89}$ William Nordhaus states that it "is crucial to have a mechanism whereby countries "graduate" into a set of obligations that are commensurate with their abilities to pay - in a way similar to the "ability to pay" principle of an income tax system, ${ }^{90}$ While we agree with the general sentiment of determining the ability to pay (our 'economic capability') in analogy to income tax paradigms for the purpose of determining fair cost/burden distributions, we do not believe that it is possible to base a 'graduation' system on ability to pay, at least not as interpreted in the Oxford Capability Measures. In other words, we believe that economic capability levels (as defined in the Oxford framework for the purpose of defining fair cost/burden shares) do not lend themselves to the introduction of country categories such as those envisaged in the 'graduation' debate.

\footnotetext{
${ }^{89}$ Review of Environmental Economics and Policy, Vol. 1, No. 1 2007: 26-44.

${ }^{90}$ Op. cit., 35.
} 
Having no (positive) capability is something that could possibly be used to define, say, a category of countries that should be exempt from taking on any sovereign mitigation target (over and above noregrets measures). However, given the diversity of countries that would have to be treated similarly because their net capabilities are of similar magnitude (such as the countries depicted in Figure IV.3.i.) it would not be acceptable to use such a category in the context of engaging in the future mitigation regime. In other words, while we do believe that similar (net) capability levels do legitimately imply similar fair cost/burden shares, following Aristotle's principle of formal equality, ${ }^{91}$ we do not think they warrant similar treatment in the mitigation regime.

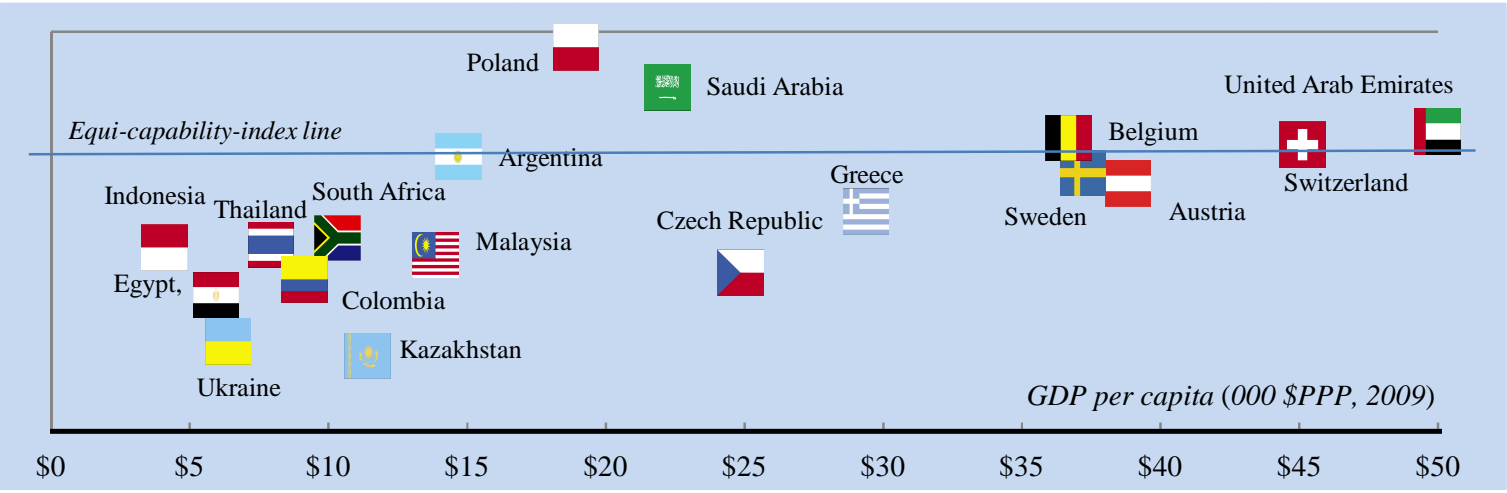

Figure IV.3.i. 'Low capability' countries?

However, the analysis that led to the formulation of the proposed Oxford Capability Measure has brought out some interesting features that we believe could possibly be adequate for such categorizations. For one, there is what might be called the 'poverty intensity of an economy' or, more precisely, the 'poverty intensity of the economy' - the number of poor people $\left(P H_{k}\right)$ times the poverty intensity index $\left(\mathrm{PII}_{k}\right.$, if available) divided by the GDP of the country:

$$
\begin{gathered}
P I E_{k}=\left(P H_{k} \times P I_{k}\right) / G D P_{k} \\
=\left(M P I_{k} \times P_{k}\right) / G D P_{k}
\end{gathered}
$$

where $M P I_{k}$ is the multidimensional poverty index of country $k$, and $P_{k}$ its population size.

The poverty intensity of GDP can be used to compare the burden of poverty on economies, reflecting, as we mentioned above, an acknowledged overriding priority for (developing) countries. Figure IV.3.ii. lists the poverty intensities for countries with an MPI and an intensity value greater than 1 poor person per $\$$ million, divided into four severity bands: 1 to 5,5 to 50,50 to 500 , and over 500 poor people per \$ million of GDP. The most striking fact about this listing is that of the 45 countries with an MPI poverty intensity greater than 50 poor/\$m GDP, only two (India and Pakistan) are not from LDCs or Africa. Figure IV.3.iii in turn depicts the geographical distribution of these four severity bands. It illustrates very clearly that with respect to the burdens of poverty, there are two hot spots: the central band of Africa, and south Asia.

91 'Treat like cases as like', [Nicomachean Ethics, V.3. 1131a10-b15; Politics, III.9.1280 a8-15, III. 12. $1282 \mathrm{~b} 18-23]$. 


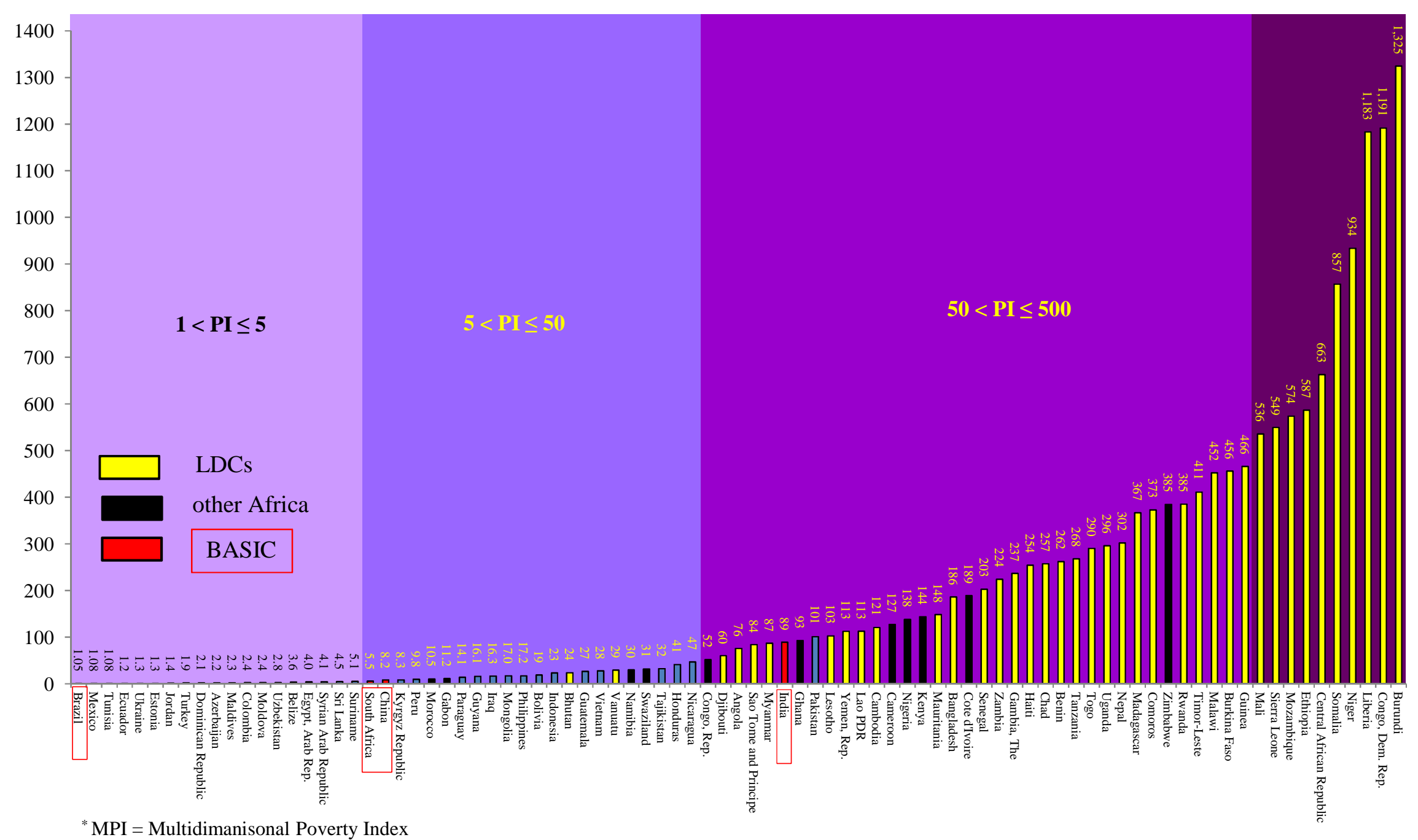

Figure IV.3.ii. Poverty intensity of GDP (PI) 


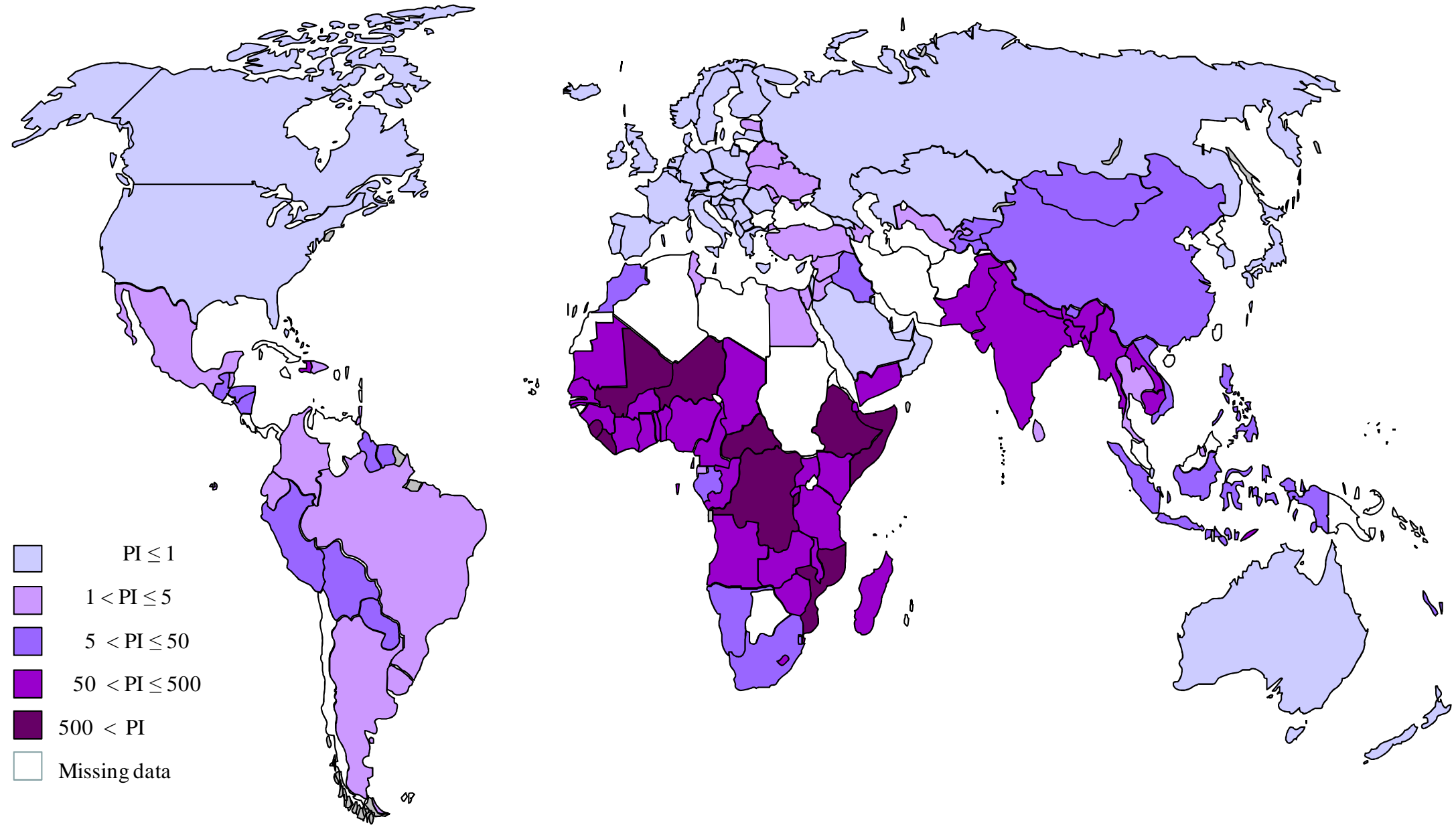

Figure IV.3.iii Poverty intensity of GDP: Geographical distribution

Note: countries w/o colour coding: no MPI or PI $<1$ 


\section{Appendix 1. Glossary}

\section{THE OXFORD CAPABILITY MEASURE AND INDEX}

\section{Base and Gross Capability Measures}

$k, n, m$ : Country indices

$G D P_{k}$ : Gross Domestic Product of country $k$

$B C M_{k}:=G D P_{k}$ : Base Capability Measure

$g d p_{k}=G D P_{k} / P_{k}:$ per capita GDP of $k\left(P_{k}:\right.$ Population size $)$

$\gamma_{k}=g d p_{k} / g d p_{w o r l d}:$ Relative prosperity parameter

$\delta$ : (Prosperity) progressiveness power parameter

$G C M_{k}^{\delta}=\left(\gamma_{k}\right)^{\delta} \times G D P_{k}$ : Gross Capability Measure (with progressiveness power $\delta$ ).

$O G C_{k}=\left(\gamma_{k}\right)^{0.5} \times G D P_{k}=\sqrt{\gamma_{k}} \times G D P_{k}:$ Oxford Gross Capability

$G C I_{k, \Gamma}^{\delta}={ }_{\text {def }} G C M_{k}^{\delta} / \sum_{i \in \Gamma} G C M_{i}^{\delta}$ [\%]: Gross Capability Index of a country $k$ within a group of countries $\Gamma(k \in \Gamma)$ with progressiveness power $\delta$,

$\Sigma_{\Gamma}^{\delta}=_{\operatorname{def}} \sum_{i \epsilon \Gamma} G C M_{i}^{\delta}$.

$\operatorname{OGCI}_{k, \Gamma}:=G C I_{k, \Gamma}^{\delta:=0.5}[\%]:$ Oxford Gross Capability Index of a country $k$ within a group of countries $\Gamma(k \in \Gamma)$.

$\Omega_{k, \Gamma}^{\delta}=\Omega \times G C I_{k, \Gamma}^{\delta}$ : part of a total cost/burden $\Omega$ allocated to $k$ within a group of countries $\Gamma(k \epsilon \Gamma)$ under a gross capability distribution with progressiveness power $\delta$.

$\omega_{k}^{\delta}={ }_{\text {def }} \Omega_{k}^{\delta} / G D P_{k}=\Omega / \Sigma_{\Gamma}^{\delta} \times\left(\gamma_{k}\right)^{\delta}:$ Gross payment rate for $k$

\section{Net Capabilities: Poverty Allowances and Poverty Adjusted Capability}

$P H_{k}\left(P H_{k}^{\Phi}\right): \quad$ Poverty Headcount = number of poor people $($ as defined by $\Phi)$

$P H_{k}^{\$ n}:$ Number of people in country $k$ below $\$ n /$ day

$P H_{k}^{\mathrm{MPI}}$ : Number of poor people in country $k$ according to the MPI methodology

MPI $\left(M P I_{k}\right): \quad$ Multidimensional Poverty Index (of country $k$ )

$P I I_{k}\left(P I_{k}^{\Phi}\right)$ : Poverty Intensity Index (as defined by $\Phi$ )

$$
\begin{aligned}
& P I I_{k}^{M P I}=P_{k} \times M P I_{k} / P H_{k}^{\mathrm{MPI}} \quad \text { (hence } P I I_{k}^{M P I} \times P H_{k}^{\mathrm{MPI}}=P_{k} \times M P I_{k} \text { ) } \\
& P I I_{k}^{\$ n} \equiv 1
\end{aligned}
$$

П: $\quad$ General poverty capability allowance [per poor person per year].

$\Pi_{k}=\Pi \times P I I_{k}\left(\Pi_{k}^{\Phi}\right)$ : Poverty intensity adjusted (country specific) capability allowance (as defined by $\Phi)$.

$P C A_{k}^{\Pi}=\Pi_{k} \times P H_{k}\left(P C A_{k}^{\Pi, \Phi}\right):$ Poverty Capability Adjustment with $\Pi$ (as defined by $\left.\Phi\right)$; 


$$
P C A_{k}^{\Pi, M P I}=\Pi \times P_{k} \times M P I_{k}: \text { MPI-based Poverty Capability Adjustment. }
$$

$N C M_{k}^{\delta, \Pi}=G C M_{k}^{\delta}-P C A_{k}^{\Pi}\left(N C M_{k}^{\delta, \Pi, \Phi}\right):$ Net Capability Measure with progressiveness power $\delta$ and poverty capability allowance $\Pi$ (as defined by $\Phi)$.

$\Pi_{k}^{\delta, 0}:$ Zero capability allowance for $k$ (with progressiveness power $\delta$ ) $: N C M_{k}^{\delta, \Pi_{k}^{\delta, 0}}=0$.

$\Pi_{x \Gamma}^{\delta, 0}: x \times$ average zero capability allowance of $k \in \Gamma$.

$P C A_{k}=\Pi_{2 L D C}^{0} \times P_{k} \times M P I_{k}:$ Oxford Poverty Capability Adjustment ( $\Gamma=$ LDC Group).

$O C M_{k}=O G C_{k}-P C A_{k}=\sqrt{\gamma_{k}} \times G D P_{k}-\Pi_{2 L D C}^{0} \times P_{k} \times M P I_{k}:$ Oxford Capability Measure.

$O C I_{k}=O C M_{k}^{+} / O C M_{W o r l d}^{+}:$Oxford Capability Index, with

$$
O C M_{k}^{+}=\max \left(O C M_{k}, 0\right) \text {, and } O C M_{W o r l d}^{+}=\sum O C M_{k}^{+} \text {. }
$$

\section{The Greenhouse Development Rights (GDR) Approaches}

$\operatorname{CapInc}_{k}^{\tau}=\sum_{p \in k: y_{p} \geq \tau}\left(y_{p}-\tau\right):$ GDR Capable Incomes with $y_{p}$ the income of person $p$ (in country $k)$, and $\tau$ the GDR development threshold.

$C I_{k}=\operatorname{CapInc}_{k}^{\$ 9000} / \sum_{n} \operatorname{CapInc}_{n}^{\$ 9000}:$ GDR-2 Capacity Indicator

IV. The Oxford Measure: Discussion and illustrative examples

$A C S_{k}:$ Actual cost shares

$B C S_{k}$ : Benchmark cost shares

$E C S_{k}={ }_{\text {def }} A C S_{k}-B C S_{k}:$ Excess Cost Shares

$E_{C S}^{+}=_{\text {def }} \sum_{k} E C S_{k}^{+}$with $E C S_{k}^{+}={ }_{\text {def }} \max \left(E C S_{k}, 0\right):$ Level of Inequity

$E C T_{k}={ }_{\text {def }} E C S_{k} \times \Omega:$ Excess Cost Transfers from $\left(E C T_{k}<0\right)$ or to $\left(E C T_{k}>0\right) k$, with $\Omega=$ the total cost involved.

$H D_{k, t}^{g}$ : The Growth Headroom for a country $k$ with negative capability in time $t$

$P I E_{k}=\left(P H_{k} \times P I_{k}\right) / G D P_{k}=\left(M P I_{k} \times P_{k}\right) / G D P_{k}:$ Poverty Intensity of the Economy (GDP) 


\section{Appendix 2. Estimating the Power of Prosperity Progressivity ( $\delta$ )}

In the literature on income tax progressivity, tax liability progressivity is often captured by the ratio of the marginal rate of tax to the average rate of tax of an individual. The intuition behind this measure is simply that if the marginal rate is greater than the average rate, then the average tax rate paid by that individual will increase with their income. ${ }^{92}$

Consider now the climate change capability scheme where, according to the definition of capability as a tax base or total liability, the country $k$ pays an amount of tax $\Omega_{k}$ that is set as a proportion $\Omega$ of their total capability $\left(f\left(\gamma_{k}\right) \times G D P_{k}\right)$ :

$$
\Omega_{k}=\Omega \times f\left(\gamma_{k}\right) \times g d p_{k} \times P_{k}
$$

where $g d p_{k}$ is the per capita GDP figure for country $k, P_{k}$ its population, and $f\left(\gamma_{k}\right)$ is a function that amends capability (from being proportional to GDP) in a way that depends on income per capita relative to the world average $\left(\gamma_{k}\right)$. The payment by $k$ 's typical resident for each unit of their income is called the average payment rate and is:

$$
\tau_{a k}=\Omega / \Sigma_{\Gamma} \times f\left(\gamma_{k}\right)
$$

where $\Omega$ is the total cost to be shared and the total capability of the group of countries $\Gamma$ involved in sharing $\Omega$ is $\Sigma_{\Gamma}$ (see Section II.1.4).

The marginal payment rate for $k$ 's typical resident is:

$$
\tau_{m k}=\Omega \times\left[\left(f^{\prime}\left(\gamma_{k}\right) \times \gamma_{k}\right)+f\left(\gamma_{k}\right)\right]
$$

Therefore the ratio of marginal to average payment rates is a measure of liability progression and is given by:

$$
\frac{\tau_{m k}}{\tau_{a k}}=\left(\frac{f^{\prime}\left(\gamma_{\mathrm{k}}\right) \times \gamma_{\mathrm{k}}}{f\left(\gamma_{k}\right)}+1\right)
$$

In the case of the Oxford Measure, where $f\left(\gamma_{k}\right)=\left(\gamma_{k}\right)^{\delta}$, the measure of progression is simply:

$$
\frac{\tau_{m k}}{\tau_{a k}}=1+\delta
$$

Using this calculation, our strategy is to use estimates of the marginal to average personal income tax rates of countries to infer a degree of prosperity progressivity that they have been using domestically, and calibrate $\delta$ accordingly.

In reality, there is a different degree of progressivity for each level of income. Which level of income would be the most reasonable basis for calibrating an internationally comparable capability scheme? Presumably this would be at the average income - the closest comparator to GDP per capita. Yet, in all the studies we analysed, we found only reported estimates of the cross-population averages of the marginal income tax rate and of the average income tax rate.

Consider that the population of tax units in a country is distributed with frequency $p(y)$ for income levels $y$ and that the total tax paid from income $y$ is $g(y)$.

Hence the average income is:

$$
\bar{y}=\int y \times p(y) d y
$$

\footnotetext{
92 'Progressivity of Income Tax Systems', Norregaard, John, OECD Economic Studies, No 15, Autumn, 1990.
} 
Table A2.1. Estimates of average and average marginal tax rates.

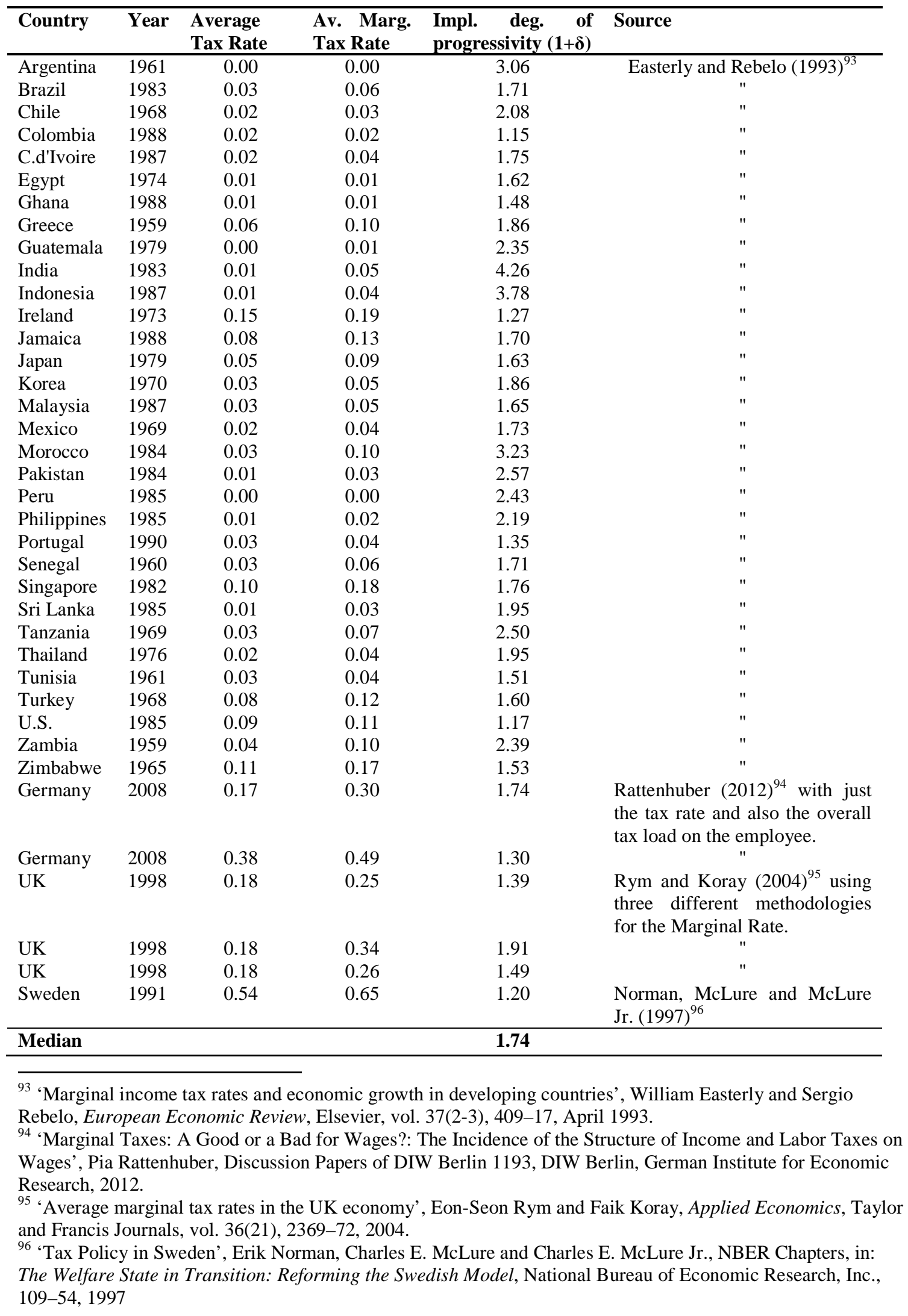


and the ratio of marginal to average taxes of the individual earning average income is:

(A2.7)

$$
g^{\prime}(\bar{y}) \times \bar{y} / g(\bar{y})
$$

On the other hand, the cross-population average of marginal tax rates divided by the cross-population average of average tax rates is:

$$
\int g^{\prime}(y) \times p(y) d y / \int \frac{g(y)}{y} \times p(y) d y
$$

The question is, how well do the two measures of a country's progressivity correspond? It turns out that if the tax function is precisely of the form we are interested in $-g(y)=(y)^{1+\delta}$ - then these two formulae yield the same estimate of liability progression, $1+\delta$. Hence, insofar as we are approximating a capability function of this form, we feel justified in using data on the average marginal and average rates across the tax population to infer a rough approximation to $\delta$.

Table A.2.1 reports estimates found in the literature. As we can see, the median value across all studies is 1.74 . As this might be dominated by Easterly and Rebelo's large cross-country study, we also note that the median of the remaining studies is 1.44 . Thus a liability progressivity of 1.5 (implying $\delta=0.5$ ) seems a reasonable value to use in our calibrations. 


\section{Appendix 3. The Poverty Capability Allowance (ח)}

\section{Choosing П}

Apart from a power of progressivity parameter $\delta$, the Oxford measure also requires the determination of the universal poverty allowance per poor person $(\Pi)$, which needs some motivation. The fact is, this choice would ultimately have to be political, which is why we propose to make use of a common thread in all proposals of differentiated treatment that have been suggested by Parties in the past, namely that Least Developed Countries would be exempt from taking on obligations. The idea, therefore, is to set the allowance so as to ensure that (most) LDCs will have no capability.

In Section IV. 2 we defined the Zero Capability Allowance of each country as the level of poverty allowance for which capability is zero. Figure A3.1 plots the zero capability allowances of LDCs and sub-Saharan African non LDCs (excluding South Africa). The average across all LDCs is shown by the dotted red line. In order to exclude nearly all LDCs, we set the general poverty capability allowance $(\Pi)$ at twice this level, as indicated by the solid red line.

There may well be other ways in which one might try to find an acceptable level for this parameter. Indeed, one might consider (a prosperity progressively adapted version of) the development threshold proposed in the GDR approach (see Section III), but we believe that the choice of the LDC Group as calibrating 'reference group' may be less controversial than any of these alternatives.

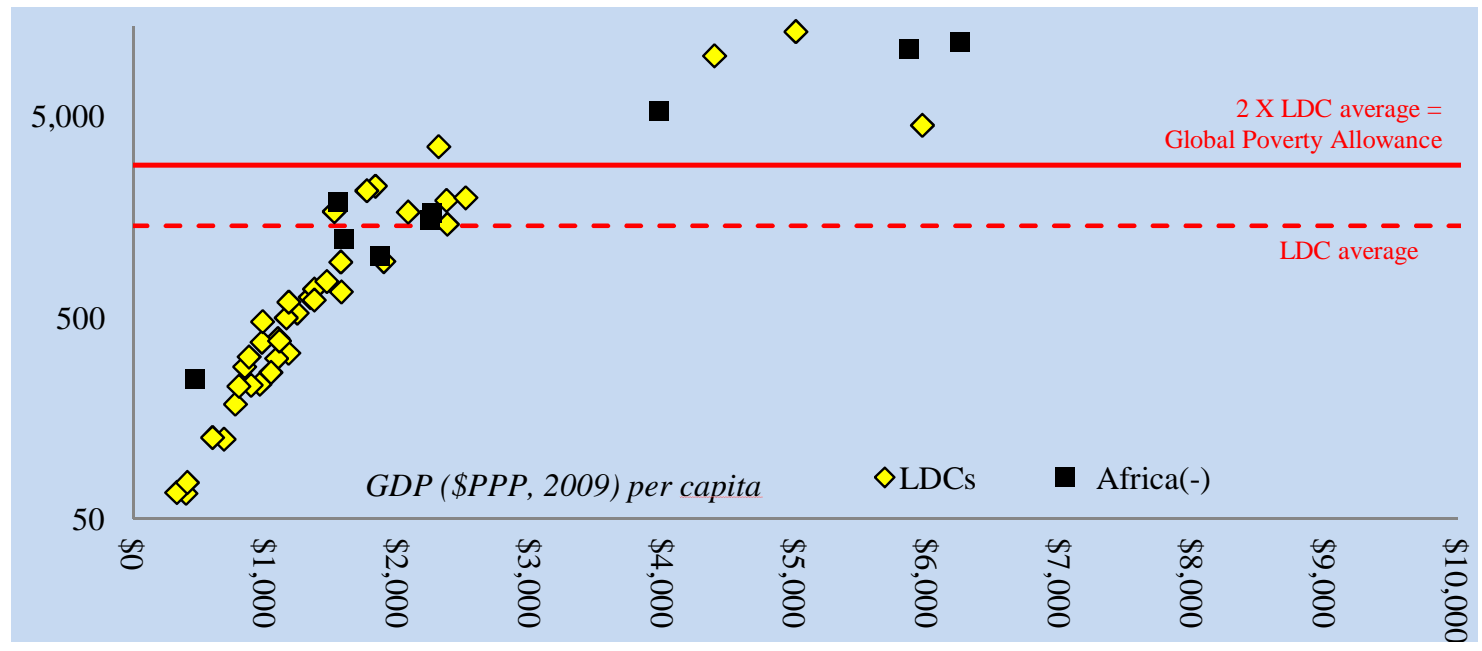

Figure A3.1 Zero Capability Allowances

\section{SENSITIVITY OF CAPABILITY (INTENSITY) TO П}

Having chosen the general poverty capability allowance $\Pi$, it is worth illustrating its importance in shaping the capabilities of countries, which we do by considering how changes in $\Pi$ affect the capabilities, or to be more precise, the capability intensities of GDP $\left(O C M_{k}^{\delta, M P I} / G D P_{k}\right)$ of different countries, as depicted in Figure A.3.2 below. 
General Poverty Allowance $(\Pi)=$ LDC Zero Capability Allowance $x$

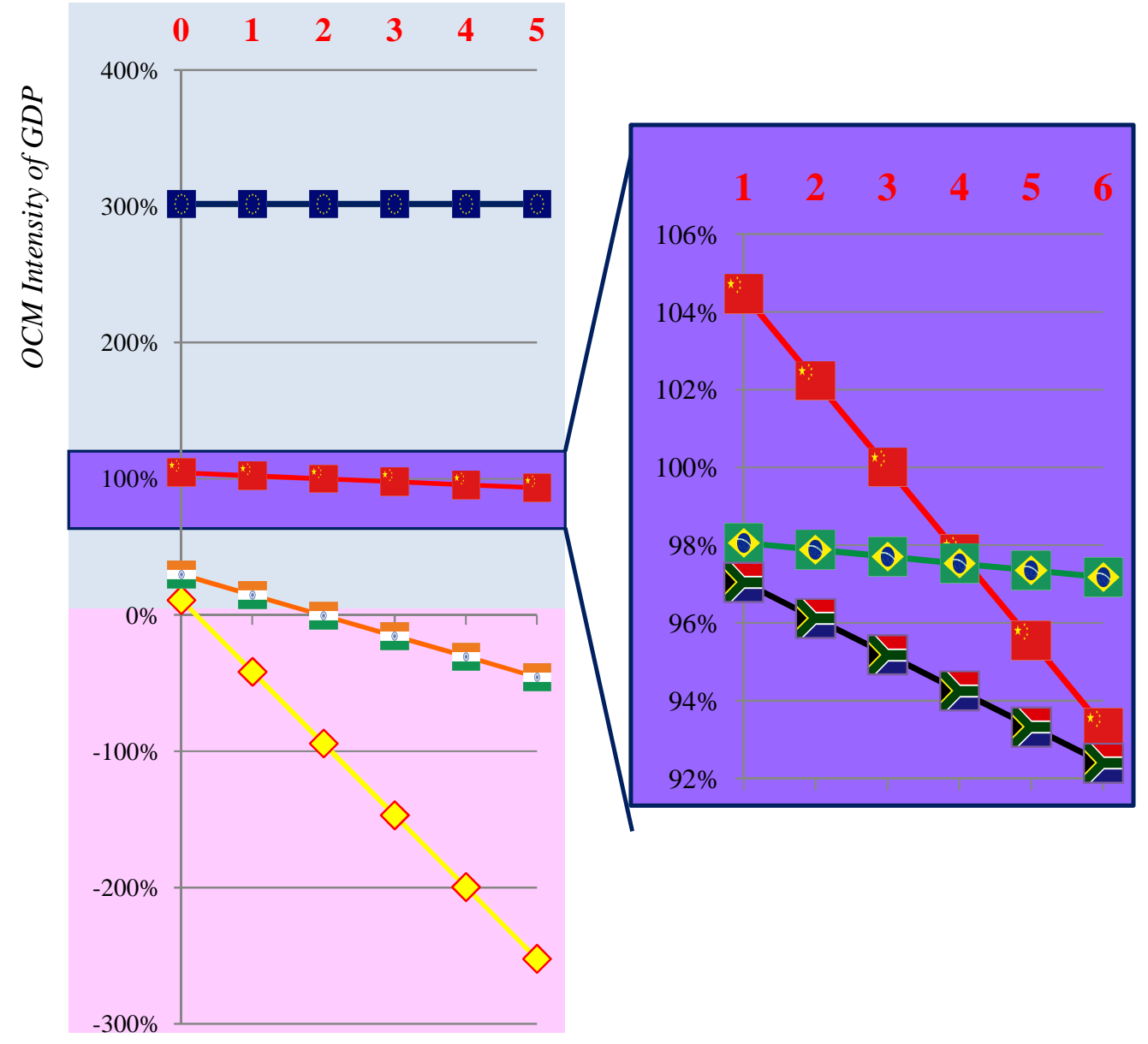

Figure A3.2 Capability Intensity: Sensitivity to Global Poverty Allowance

The figure describes the response of the OCMs of Brazil, China, the EU, India, and LDCs to the Global Poverty Allowance. Each nation-group's path is traced by its flags, and, in the case of LDCs, by a yellow diamond. The intercept with the y-axis on the left is the special case of gross capability (i.e. for $\Pi_{k}=0$ ), at which the OCM intensity of GDP is equal to $\sqrt{\gamma_{k}}$ which means that $100 \%$ corresponds to having world average per capita GDP. From then on the slope of each nation-group's line reflects the poverty intensity of GDP and for this reason, the slopes can differ quite sharply. Thus, for example, India's capability (per unit of GDP) is much more sensitive to the poverty allowance than China's because of its many poor.

To show this formally, we can differentiate the Oxford capability intensity with respect to the general poverty capability allowance (П) to give the slope as:

$$
\text { (A.3.1) } \frac{d}{d \Pi}\left(O C M_{k}^{\delta, \mathrm{MPI}} / G D P_{k}\right)=\left(P_{k} \times M P I_{k}\right) / G D P_{k}
$$

such that the MPI 'multidimensional headcount' $\left(h_{k} \times P_{k}\right)$ multiplied with the 'intensity (or breadth) of poverty' $\left(a_{k}\right.$, see Section II.2.2), per unit of GDP reflects the MPI poverty intensity of GDP (see also Section IV.3). 